\title{
Review \\ Immunotherapy for Colorectal Cancer: Mechanisms and Predictive Biomarkers
}

\author{
Lindsey Carlsen ${ }^{1,2,3,4,5}$, , Kelsey E. Huntington ${ }^{1,2,3,4,5}$ (D) and Wafik S. El-Deiry ${ }^{1,2,3,4,5,6, *(\mathbb{D})}$ \\ 1 Laboratory of Translational Oncology and Experimental Cancer Therapeutics, The Warren Alpert Medical \\ School, Brown University, Providence, RI 02903, USA; lindsey_carlsen@brown.edu (L.C.); \\ kelsey_huntington@brown.edu (K.E.H.) \\ 2 The Joint Program in Cancer Biology, Brown University and the Lifespan Health System, \\ Providence, RI 02903, USA \\ 3 Department of Pathology and Laboratory Medicine, The Warren Alpert Medical School, Brown University, \\ Providence, RI 02903, USA \\ 4 Pathobiology Graduate Program, The Warren Alpert Medical School, Brown University, \\ Providence, RI 02903, USA \\ 5 Legorreta Cancer Center, The Warren Alpert Medical School, Brown University, Providence, RI 02903, USA \\ 6 Hematology-Oncology Division, Department of Medicine, Rhode Island Hospital and Brown University, \\ Providence, RI 02903, USA \\ * Correspondence: wafik@brown.edu
}

check for updates

Citation: Carlsen, L.; Huntington, K.E.; El-Deiry, W.S. Immunotherapy for Colorectal Cancer: Mechanisms and Predictive Biomarkers. Cancers 2022, 14, 1028. https://doi.org/ 10.3390/cancers14041028

Academic Editor: Jan Willem B. de Groot

Received: 30 December 2021

Accepted: 9 February 2022

Published: 17 February 2022

Publisher's Note: MDPI stays neutral with regard to jurisdictional claims in published maps and institutional affiliations.

Copyright: (C) 2022 by the authors. Licensee MDPI, Basel, Switzerland. This article is an open access article distributed under the terms and conditions of the Creative Commons Attribution (CC BY) license (https:// creativecommons.org/licenses/by/ $4.0 /)$.
Simple Summary: Late-stage colorectal cancer treatment often involves chemotherapy and radiation that can cause dose-limiting toxicity, and therefore there is great interest in developing targeted therapies for this disease. Immunotherapy is a targeted therapy that uses peptides, cells, antibodies, viruses, or small molecules to engage or train the immune system to kill cancer. Here, we discuss the preclinical and clinical development of immunotherapy for treatment of colorectal cancer and provide an overview of predictive biomarkers for such treatments. We also consider open questions including optimal combination treatments and sensitization of colorectal cancer patients with proficient mismatch repair enzymes.

Abstract: Though early-stage colorectal cancer has a high 5 year survival rate of $65-92 \%$ depending on the specific stage, this probability drops to $13 \%$ after the cancer metastasizes. Frontline treatments for colorectal cancer such as chemotherapy and radiation often produce dose-limiting toxicities in patients and acquired resistance in cancer cells. Additional targeted treatments are needed to improve patient outcomes and quality of life. Immunotherapy involves treatment with peptides, cells, antibodies, viruses, or small molecules to engage or train the immune system to kill cancer cells. Preclinical and clinical investigations of immunotherapy for treatment of colorectal cancer including immune checkpoint blockade, adoptive cell therapy, monoclonal antibodies, oncolytic viruses, anti-cancer vaccines, and immune system modulators have been promising, but demonstrate limitations for patients with proficient mismatch repair enzymes. In this review, we discuss preclinical and clinical studies investigating immunotherapy for treatment of colorectal cancer and predictive biomarkers for response to these treatments. We also consider open questions including optimal combination treatments to maximize efficacy, minimize toxicity, and prevent acquired resistance and approaches to sensitize mismatch repair-proficient patients to immunotherapy.

Keywords: colorectal cancer; immunotherapy; checkpoint blockade; adoptive cell therapy; monoclonal antibodies; oncolytic viruses; anti-cancer vaccines; cytokine; T cell; NK cell

\section{Introduction}

Colorectal cancer (CRC) is a deadly disease with a 5 year survival rate of $13 \%$ when metastatic. Among all types of cancer, CRC is the third deadliest and the incidence of this disease among young people is rising in developing nations [1]. Treatment options for 
CRC include surgery, chemotherapy, radiation, targeted therapy, and immunotherapy (IT). Chemotherapy regimens generally include 5-fluorouracil (5-FU) as a single agent or in combination with either oxaliplatin, irinotecan, or both. 5-FU or capecitabine (prodrug of 5-FU) combined with oxaliplatin is commonly given to stage II and III CRC patients, while 5-FU, oxaliplatin, and irinotecan are generally administered to stage IV patients. Radiation is most commonly given to stage II-IV rectal cancer patients. Chemotherapy and radiation can elicit severe toxicities in patients, and IT is a promising strategy that aims to kill cancer cells more selectively compared to these traditional treatment options [2].

CRC is classified based on genetic alterations present in the tumor such as mutations in APC, KRAS, BRAF, p53, and mismatch repair (MMR) enzymes [3]. Likely the most relevant genetic alterations in terms of response to IT are those in MMR enzymes. MMR enzymes repair DNA defects, and mutations that lead to MMR deficiency (dMMR) cause an accumulation of mutations at microsatellite regions (also known as short tandem repeats) [4]. Patients with dMMR tumors are classified as microsatellite instable (MSI). MSI tumors can also be referred to as dMMR, MSI+, or MSI-high (MSI-H), whereas patients with proficient MMR enzymes (pMMR) are referred to as microsatellite stable (MSS). MSI status is generally independent of pathological stage. The accumulation of mutations in MSI-H tumors results in the presentation of a large repertoire of neoantigens, commonly referred to as high neoantigen burden [5]. Often, high neoantigen burden improves response to IT in patients with MSI-H tumors as compared to patients with MSS tumors. Some clinical trials have reported benefit of IT exclusively in patients with MSI-H tumors [2]. MSI-H is detected in only approximately $15 \%$ of CRC tumors [6], and thus IT is generally ineffective for the majority of CRC patients. Uncovering ways to sensitize MSS CRC to IT is a major area of interest.

IT includes a wide variety of different therapies that engage or train the immune system to kill cancer cells. Different types of IT include immune checkpoint blockade (ICB), adoptive cell therapies (ACT), monoclonal antibodies (mAbs), oncolytic viruses, anti-cancer vaccines, and immune system modulators. Numerous preclinical studies have demonstrated promising results and have been translated into clinical trials. While many of these trials are ongoing, some ITs are currently approved for CRC including mAbs that target cancer-associated antigens, namely panitumumab (anti-EGFR), cetuximab (antiEGFR), and bevacizumab (anti-VEGF) [7]. Several ICB therapies are also FDA-approved. The $\mathrm{mAb}$ pembrolizumab (anti-PD-1) was approved in May 2017 based on results from the KEYNOTE-028 trial, which resulted in a 40\% objective response rate in patients with MSI-H tumors [8]. The mAbs nivolumab (anti-PD-1) and ipilimumab (anti-CTLA-4) are also FDA-approved for patients with MSI-H metastatic CRC (mCRC) $[9,10]$. The clinical success of ICB therapy in specific CRC patient populations has made it highly relevant in the field of cancer IT. It is of great importance to consider combinations of ICB with other types of IT to improve responses.

Additional work has been performed as far as biomarker development to identify groups of CRC patients who are likely to benefit from IT. Promising biomarkers have been identified and are based on specific genetic alterations present in CRC tumors, the CRC tumor microenvironment (TME), and analytes that are detectable within patient serum (i.e., liquid biomarkers). This review will discuss the molecular bases of ITs that have been investigated preclinically and clinically for treatment of CRC, provide an overview of current predictive biomarkers for IT in CRC, will consider future requisite topics of investigation including identification of optimal combination treatments and investigation of methods to sensitize MSS CRC to IT.

\section{Colorectal Cancer Response to Immunotherapy}

The low 5 year survival rate (13\% for $\mathrm{mCRC}$ ) [1], development of resistance to standard therapies, and dose-limiting side effects of cytotoxic drug treatments have inspired the investigation and development of more targeted therapies for treatment of CRC. IT is a promising candidate for treatment of $\mathrm{mCRC}$, especially for patients with MSI-H tumors [2]. 
In this section, we detail the molecular mechanisms of ITs that have been investigated clinically or preclinically for treatment of CRC. The molecular action and cellular expression of relevant targets are listed in Table 1.

Table 1. The molecular action and cellular expression of targets relevant to IT in CRC.

\begin{tabular}{|c|c|c|c|}
\hline Target & Expressed by & Molecular Action & Ref. \\
\hline PD-1 & CD8+ T cells, CD4+ T cells & Suppresses CD8/4+ T cell activity & {$[11,12]$} \\
\hline PD-L1 & Cancer cells, APCs & Suppresses CD8/4+ T cell activity & {$[11,12]$} \\
\hline CTLA-4 & CD8+ T cells, CD4+ T cells, $\mathrm{T}$ regs & $\begin{array}{l}\text { Suppresses CD } 8 / 4+\mathrm{T} \text { cell activity } \\
\text { Enhances T reg activity }\end{array}$ & [13] \\
\hline LAG-3 & CD8+ T cells, CD4+ T cells, $\mathrm{T}$ regs, NK cells & $\begin{array}{l}\text { Suppresses CD8 / } 4+\mathrm{T} \text { cell activity } \\
\text { Enhances T reg activity }\end{array}$ & [14] \\
\hline TIM-3 & IFN- $\gamma$-producing T cells, T regs, NK cells, APCs & $\begin{array}{c}\text { Suppresses T cell, NK cell, and APC activity } \\
\text { May enhance T reg activity }\end{array}$ & [14] \\
\hline NKG2 & NK cells, some CD8+ T cells & $\begin{array}{l}\text { NKG1A/B: Suppresses NK cell activity } \\
\text { NKG2D: Enhances NK cell activity }\end{array}$ & {$[15,16]$} \\
\hline EpCAM/CD326 & Cancer cells & $\begin{array}{c}\text { Upregulates oncogene expression and cell } \\
\text { proliferation }\end{array}$ & [17] \\
\hline EGFR & Cancer cells & Triggers cell proliferation & [18] \\
\hline VEGF & Cancer cells & Stimulates angiogenesis & [18] \\
\hline CD133 & Cancer stem cells & Play a role in chemotherapy resistance & [19] \\
\hline HER3 & Cancer cells & Promotes cell proliferation & {$[20,21]$} \\
\hline HER2 & Cancer cells & Promotes cell proliferation & {$[22,23]$} \\
\hline CD3 & CD8+ T cells, $\mathrm{CD} 4+\mathrm{T}$ cells & Used in bsTCEs to engage T cells & [24] \\
\hline GPA33 & Cancer cells & Function unclear; overexpressed in CRC & {$[25,26]$} \\
\hline GUCY2C & Cancer cells & Maintains intestinal homeostasis & [27] \\
\hline CEA & Cancer cells & $\begin{array}{l}\text { May inhibit cell differentiation, apoptosis, } \\
\text { and anoikis }\end{array}$ & {$[28]$} \\
\hline Mutant KRAS & Cancer cells & Mutation causes overactive cell proliferation & [29] \\
\hline Mutant TP53 & Cancer cells & $\begin{array}{l}\text { Mutation causes loss of tumor suppressive ability } \\
\text { and possible gain of oncogenic properties }\end{array}$ & {$[30]$} \\
\hline Angiopoietin-2 & Cancer cells & Stimulates angiogenesis & [31] \\
\hline MET & Cancer cells & $\begin{array}{c}\text { Promotes cellular proliferation, motility, migration } \\
\text { and invasion }\end{array}$ & {$[32,33]$} \\
\hline DR5 & Cancer cells & Induces apoptosis & [34] \\
\hline EphA2 & Cancer cells & Controls cell-cell repulsion or adhesion & [35] \\
\hline MUC-1 & Cancer cells & Associated with invasion, metastases & [36] \\
\hline Survivin & Cancer cells & Inhibits cell death & {$[37,38]$} \\
\hline SART3 & Cancer cells & $\begin{array}{l}\text { Spliceosome recycling factor; RNA-binding } \\
\text { protein; overexpressed in CRC }\end{array}$ & {$[39,40]$} \\
\hline IL-2 & Cancer cells, CD4+ T cells & Stimulates T cells and NK cells & {$[41,42]$} \\
\hline IL-12 & APCs & Stimulates T cells and NK cells & [41] \\
\hline IL-11 & $\begin{array}{c}\text { Epithelial cells, endothelial cells, fibroblasts, myeloid } \\
\text { cells }\end{array}$ & Tumor-promoting cytokine & {$[41,43]$} \\
\hline IL-6 & Epithelial cells, myeloid cells & Tumor-promoting cytokine & [41] \\
\hline IL-1 $\alpha$ & Epithelial cells, myeloid cells & $\begin{array}{l}\text { Multi-functional: promotes inflammatory } \\
\text { carcinogenesis; promotes antitumour immunity } \\
\text { Multi-functional: promotes inflammation-induced }\end{array}$ & {$[41,44,45]$} \\
\hline IL-1 $\beta$ & Epithelial cells, myeloid cells & $\begin{array}{c}\text { carcinogenesis; recruits antineoplastic cells, may } \\
\text { block metastatic outgrowth }\end{array}$ & {$[41,44,45]$} \\
\hline IL-33 & $\begin{array}{l}\text { Epithelial cells, endothelial cells, adipocytes, } \\
\text { fibroblasts, DCs }\end{array}$ & Recruits, activates, and degranulates eosinophils & {$[46,47]$} \\
\hline IFN- $\gamma$ & $\begin{array}{c}\text { Cancer cells, CD4+ T cells, CD8+ T cells, } \gamma \delta \mathrm{T} \text { cells, NK } \\
\text { cells }\end{array}$ & Likely a tumor-inhibiting cytokine & [48] \\
\hline STING & Widely expressed in immune and non-immune cells & Stimulates IFN genes and cellular senescence & {$[49,50]$} \\
\hline CCR5 & $\begin{array}{c}\text { Cancer cells, MDSCs, T regs, monocytes, macrophages, } \\
\text { DCs, Th1 cells, activated T cells, NK cells }\end{array}$ & $\begin{array}{c}\text { Enhances cancer cell motility; enhances MDSC and } \\
\text { T reg infiltration }\end{array}$ & {$[51,52]$} \\
\hline
\end{tabular}

CRC, colorectal cancer; IT, immunotherapy.

\subsection{Immune Checkpoint Blockade}

Under normal conditions, the body relies on immunosuppressive mechanisms to maintain immune homeostasis and self-tolerance [11,12]. These immunosuppressive mechanisms involve expression of checkpoint proteins, activation of cell death programs, and accumulation of various immunosuppressive cells. While keeping harmful immune reactions in check, these mechanisms can also be exploited by cancer cells to escape immune attack [53]. For example, immunosuppressive checkpoint proteins such as PD-1, CTLA-4, 
LAG-3, TIM-3, and NKG2A/B and are often upregulated in cancer [54]. These molecules are expressed on the surface of immune cells and, when bound by their cognate ligand, activate immunosuppressive pathways that initiate apoptosis, reduce proliferation, and/or inhibit cytokine secretion in immune cells (Figure 1). In general, ICB therapies block this inhibitory receptor binding and activate anti-tumor immune cells to cause tumor regression. The most thoroughly studied ICB therapies are anti-PD-1/PD-L1 and anti-CTLA-4. These ICB therapies have demonstrated efficacy in the clinic for CRC patients with MSI-H tumors. The clinical success of ICB has given it great relevance in the field of cancer IT and has led to the development of several new directions, including the investigation of other ICBs such as LAG-3, TIM-3, and NKG2. As with all types of IT, ICB has certain advantages and limitations (Table 2). One limitation is systemic toxicity in patients, which most commonly affects organ systems including the skin (30-50\%), the gastrointestinal system $(20-40 \%)$, and the endocrine system (10-50\%). These side effects generally include low-grade rashes, diarrhea, and endocrine changes that can be permanent [55]. In addition to these side effects, one main disadvantage of ICB is that most are formulated as mAbs, which sometimes have poor pharmacokinetic properties and tissue accessibility. Formulation of small molecules or modifying $\mathrm{mAbs}$ to be smaller could solve these issues. The last main limitation of ICB is that overall response rates in CRC have been low, particularly in the MSS patient population. Despite these limitations, ICB therapy is sensitive, specific, and the wide variety of ICBs available allow combination treatments to target multiple mechanisms, which has the potential to improve efficacy [56]. In the following subsections, we detail the fundamental mechanisms driving the anti-cancer effects of clinically relevant ICBs. We also highlight areas of requisite future investigation to improve response to ICB in CRC.

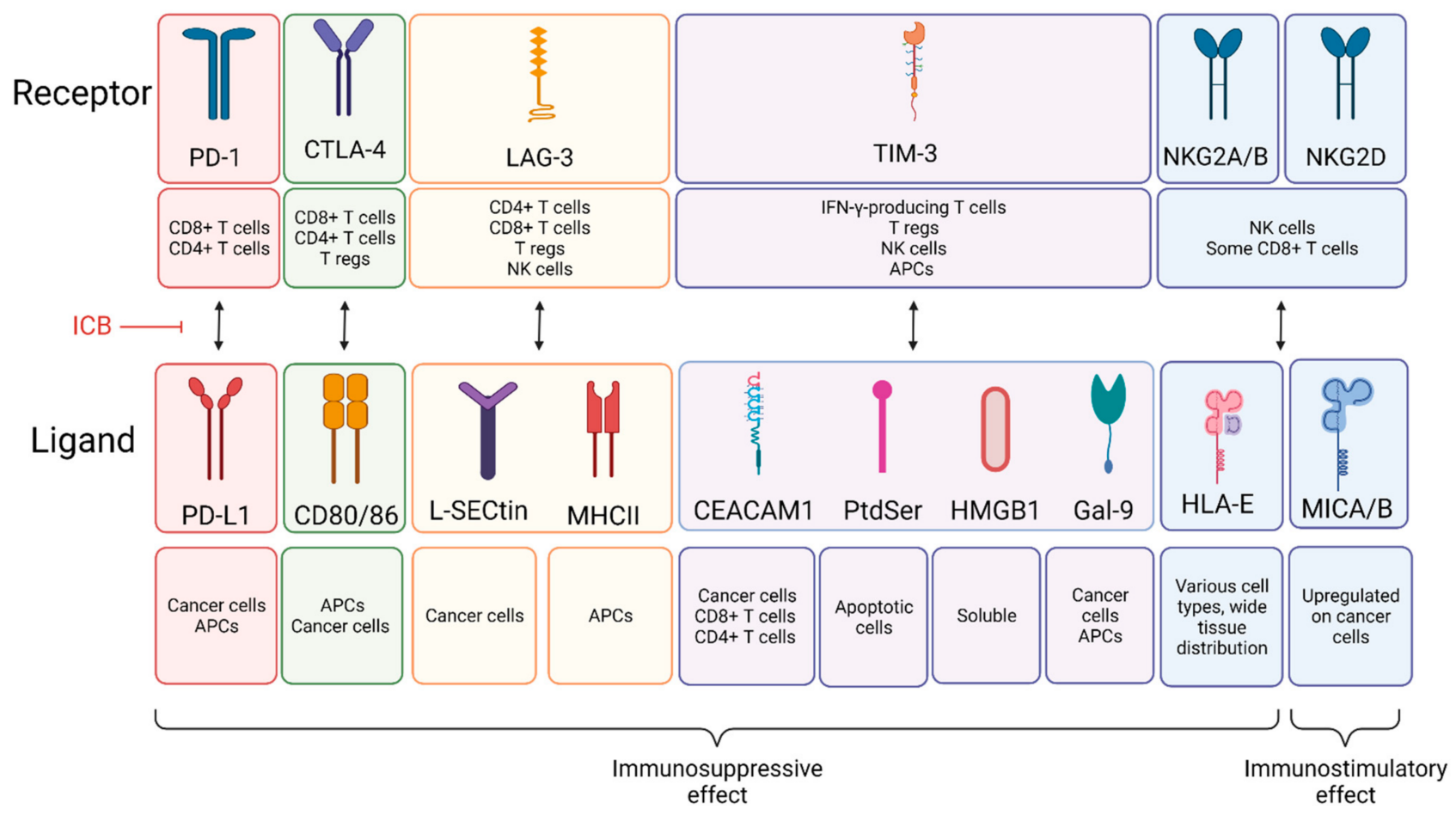

Figure 1. Immune cell and cancer cell interactions relevant to ICB therapy. CD8+ T cells, CD4+ $\mathrm{T}$ cells, NK cells, and T regs express receptors that are susceptible to binding by various cognate ligands present on the surface of colorectal cancer cells or APCs. Ligand binding results in immunosuppressive, or immunostimulatory in the case of NKG2D, signaling. ICB is a therapeutic approach involving inhibition of various receptor-ligand interactions. APC, antigen-presenting cell; ICB, immune checkpoint blockade; NK cell, natural killer cell. Created in BioRender. 
Table 2. Advantages and disadvantages of the IT approaches for treatment of CRC.

\begin{tabular}{|c|c|c|}
\hline Immunotherapy & Advantages & Disadvantages \\
\hline Immune checkpoint blockade & $\begin{array}{l}\text { Sensitive, specific, additional } \mathrm{T} \text { cell activation } \\
\text { mechanisms possible, can be combined with } \\
\text { each other }\end{array}$ & $\begin{array}{l}\text { Most are mAbs and confer the same } \\
\text { disadvantages, systemic toxicity is likely, } \\
\text { response rates are low in CRC }\end{array}$ \\
\hline Adoptive cell therapy & $\begin{array}{l}\text { Personalized, permanent } \mathrm{T} \text { cell modification } \\
\text { confers immune memory }\end{array}$ & $\begin{array}{c}\text { Expensive, difficult to manufacture, GvHD, } \\
\text { CRS and B cell aplasia common }\end{array}$ \\
\hline Monoclonal antibody & $\begin{array}{l}\text { Relatively inexpensive, specific, effective } \\
\text { across cancer types, can be conjugated easily }\end{array}$ & $\begin{array}{l}\text { Target identification expensive, inadequate } \\
\text { pharmacokinetics and tissue accessibility, } \\
\text { resistance development common }\end{array}$ \\
\hline Oncolytic virus therapy & $\begin{array}{l}\text { Specific to cancer cells, may prime immune } \\
\text { system to boost response to other ITs }\end{array}$ & Anti-viral immunity may reduce efficacy \\
\hline Cancer vaccines & Specific, can be personalized & $\begin{array}{c}\text { Rejection is possible due to delivery of } \\
\text { foreign antigens }\end{array}$ \\
\hline Immune system modulators & $\begin{array}{l}\text { Many are FDA-approved, small size } \\
\text { facilitates access to cancer cells, relatively } \\
\text { inexpensive, can stimulate general } \\
\text { anti-cancer immune response }\end{array}$ & $\begin{array}{c}\text { Low specificity possible, risk of immediate } \\
\text { onset CRS (cytokine storm] }\end{array}$ \\
\hline
\end{tabular}

Adapted from [56]. CRC, colorectal cancer; CRS, cytokine release syndrome; IT, immunotherapy; GvHD, graft versus host disease.

\subsubsection{Anti-PD-1 and Anti-PD-L1}

Programmed cell death protein 1 (PD-1) is an inhibitory receptor expressed on CD8+ and CD4+ T cells. When bound by ligand, PD-1 modulates the immune response and promotes self-tolerance by activating apoptosis in antigen-specific $\mathrm{T}$ cells and inhibiting apoptosis of regulatory T cells (T regs) [11,12]. PD-1 is bound by programmed cell death ligand 1 (PD-L1), a transmembrane protein that is often overexpressed on tumor cells [12]. Promising in vitro and in vivo preclinical studies have directed clinical trials involving PD-1/PD-L1 inhibition, ultimately resulting in the approval of several anti-PD-1 mAbs.

Clinical use of ICB therapies currently involves the FDA-approved compounds pembrolizumab, nivolumab, and ipilimumab, which can be administered to patients with MSI-H mCRC tumors [57,58]. Several months after the approval of pembrolizumab in May 2017, nivolumab was approved based on results from the CheckMate 142 trial, which demonstrated a $31.1 \%$ objective response rate in patients with MSI-H tumors. Nivolumab combined with the anti-CTLA inhibitor ipilimumab was approved in July 2018 after further analysis of the CheckMate 142 trial revealed that patients in this combination treatment group had a $55 \%$ objective response rate [8]. Nivolumab can be given alone or in combination with ipilimumab to patients who have progressed after chemotherapy. In 2020, pembrolizumab was approved as a first-line treatment for patients with MSI-H CRC tumors based on the results from the KEYNOTE-177 clinical trial, which reported a median progression-free survival (PFS) of 16.5 months for MSI-H CRC patients treated with firstline pembrolizumab and 8.2 months for patients treated with chemotherapy (HR 0.60; 95\% CI, 0.45-0.80; $p=0.0002)[59,60]$. Recent evidence supports the use of ICB as a frontline treatment. In addition to positive results from the KEYNOTE-177 trial, a phase II trial involving neoadjuvant treatment of MSI-H CRC patients with the anti-PD-1 mAb toripalimab caused a high pathological complete response rate and an acceptable safety profile [61]. In general, anti-PD-1 therapy causes a slightly increased rate of side effects compared to anti-PD-L1 therapy [55].

There are several ongoing clinical trials evaluating the use of ICB in the adjuvant setting. These include evaluation of the PD-L1 inhibitor atezolizumab plus FOLFOX compared to FOLFOX alone in MSI-H CRC patients [62], and evaluation of the antiPD-L1 compound avelumab following 5-FU-based treatment compared to 5-FU-based treatment alone in patients with stage III MSI-H or POLE-mutant CRC [63]. Other clinical trials have tested combination therapies that might improve ICB efficacy in MSS CRC patients with varying results. Combinations of regorafenib (tyrosine kinase inhibitor) and 
nivolumab initially revealed promising results [64], but this treatment resulted in only modest clinical activity in patients with MSS CRC [65]. A phase II study of pembrolizumab plus capecitabine and bevacizumab revealed an acceptable safety profile and some level of efficacy in MSS CRC patients who have received prior fluoropyrimidine-based therapy. [66].

Recent in vivo investigation points to low levels of tumor-infiltrating dendritic cells (DCs) as a reason for limited response to anti-PD-1/PD-L1 mAbs in MSS tumors. In this study, subcutaneous injection of MSS CRC cells in mice led to the development of tumors that were responsive to ICB whereas orthotopic injection of CRC cells into the liver resulted in tumors that were resistant to ICB. Comparing these tumors revealed that the resistant liver tumors had a significantly lower number of DCs compared to the sensitive subcutaneous tumors. A similar observation was made in liver metastases of CRC patients. As DCs are required for antigen presentation and activation of CD8+ T cells, their low numbers likely contribute to the resistance of liver mCRC cell tumors. This points to combination treatments with ICB and Flt-3 Ligand (FLT3L), a cytokine that promotes the differentiation and/or expansion of immature DCs $[67,68]$. Further investigation of this nature is needed to determine optimal drug combinations to enhance efficacy of ICB.

\subsubsection{Anti-CTLA-4}

Cytotoxic T-lymphocyte-associated protein 4 (CTLA-4) is an inhibitory receptor expressed primarily by CD4+ and CD8+ T cells. Antigen-presenting cells (APCs) and cancer cells express the CTLA-4 ligands CD80 and CD86. These ligands can bind to either CTLA-4 or CD28, resulting in a co-inhibitory or costimulatory response, respectively. Binding of CTLA-4 to CD80 or CD86 results in either cell-intrinsic (affecting the T cell) or cell-extrinsic (affecting the secondary cell) immunosuppressive signaling, though most evidence suggests that the CTLA-4 pathway functions primarily through cell-extrinsic mechanisms [13]. CLTA-4 is also expressed on regulatory T cells (T regs, FOXP3+). When CTLA-4 on T regs binds to CD80/86 on APCs, priming and activation of naïve CD4+ T cells by APCs is blocked [69]. In CRC, the anti-CTLA-4 mAb ipilimumab combined with nivolumab is approved for patients with MSI-H mCRC [57]. Strikingly, this combination in the neoadjuvant setting for treatment of early-stage colon cancer resulted in a 100\% pathological response in patients with MSI-H tumors and a $27 \%$ response rate in MSS tumors after only 4 weeks of treatment [70]. ICB-related toxicity occurs more frequently in patients receiving antiCTLA-4 therapy compared to patients receiving anti-PD-1/PD-L1 therapies [55]. Similar to anti-PD-1/PD-L1 therapies, optimal treatment timing and therapy combinations need to be optimized to improve response rates to anti-CTLA-4 ICB therapy, especially in patients with MSS tumors.

\subsubsection{Anti-LAG-3}

Lymphocyte activation gene-3 (LAG-3) is an inhibitory receptor that is expressed by CD4+ and CD8+ T cells, T regs, and NK cells. LAG-3 on CD4+ cells likely interacts with MHC class II on antigen-presenting cells, while LAG-3 on CD8+ T cells and NK cells likely interacts with L-SECtin on cancer cells. These interactions inhibit immune activity by suppressing $\mathrm{T}$ cell proliferation, cytokine production, and Ca2+ flux. LAG-3 on $\mathrm{T}$ regs stimulates $\mathrm{T}$ reg-mediated immune suppression. The precise mechanisms by which LAG-3 mediates these effects remain to be clarified [14], an important topic of future investigation if optimal treatment combinations are to be established. Several phase II studies are underway to investigate the anti-PD-1 mAbs nivolumab or dostarlimab in combination with other therapies including an anti-LAG-3 antibody [71-73]. One trial will specifically investigate responses in patients with MSS tumors [72], the results of which are highly anticipated due to the inefficacy of anti-PD-1/PD-L1 and anti-CTLA-4 ICBs for this patient population. 


\subsubsection{Anti-TIM-3}

$\mathrm{T}$ cell immunoglobulin- and mucin-domain-containing-3 (TIM-3), also known as hepatitis A virus cellular receptor 2 (HAVCR2), is expressed on IFN- $\gamma$-producing T cells, T reg cells, NK cells, and APCs such as macrophages and DCs. In CD8+ cells, TIM-3 marks a dysfunctional or exhausted phenotype and limits effector function [14].

TIM-3 ligands include cell surface proteins CAECAM1, phosphatidyl serine (PtdSer), soluble protein high mobility group box 1 protein (HMGB1), and galectin-9 (Gal-9), which can be expressed on the cell surface or can be secreted [14]. CEACAM1 is primarily expressed on cancer cells but can also be expressed on CD8+ and CD4+ T cells. PtdSer is expressed on apoptotic cells, and Gal-9 is expressed on cancer cells and APCs. HMGB1 is a soluble protein that binds to DNA from dying cells [14] (Figure 1).

CEACAM1 is expressed constitutively on epithelial cells and in a regulated manner on immune cells depending on their activation state. Defective CEACAM1 inhibits TIM-3-mediated inhibitory signaling, suggesting that TIM-3 is dependent on CEACAM1 for proper functioning [14]. Co-inhibition of TIM-3 and CEACAM1 results in improved elimination of CRC tumors in mice [74]; however, no clinical trials are currently investigating this combination for CRC. PtdSer is released when cells undergo apoptosis and directly regulates TIM-3 function [75]. HMGB1 binds DNA released from dying cells and mediates cytokine production and activation of an innate immune reaction that is inhibited upon TIM-3-HMGB1 binding [14]. Gal-9 is expressed on and can be secreted by tumor cells and APCs, and upon its binding to TIM-3 induces cell death in Th1 cells. Most anti-TIM-3 therapies target its interaction with CEACAM1 or PtdSer [76]. Recent investigation revealed that PD-1 physically interacts with Gal-9 and TIM-3 and attenuates Gal-9/TIM-3-induced apoptosis [77]. There is currently one clinical trial (NCT02817633) recruiting patients with advanced solid tumors for treatment with TSR-022, an anti-TIM-3 antibody [78]. Further investigation of anti-TIM-3 tumor suppressive mechanisms and its clinical utility is needed to optimize treatment combinations with other ITs. It is clear that while the driving mechanisms of different ICBs are similar, their cellular expression patterns differ which could have a profound effect on their roles in anti-tumor immunity and could translate to synergistic mechanisms when these therapies are combined.

\subsubsection{Anti-NKG2}

The Natural Killer Group 2 (NKG2) family of receptors is expressed on a majority of NK cells and a subset of CD8+ T cells. Different NKG2 isoforms activate either immunosuppressive or immunostimulatory pathways. There are five isoforms, namely NKG2A, NKG2B, NKG2C, NKG2D, NKG2E, and NKG2F [15]. Inhibitory NKG2 receptors include NKG2A and NKG2B, while stimulatory receptors include NKG2C, NKG2D [16], and NKG2E. NKG2F has an unknown function. NKG2A/B bind to HLA-E, a ligand expressed at low levels with a wide tissue distribution $[15,79]$. Binding inhibits myriad things including $\mathrm{Ca}^{2+}$ influx, degranulation, cytokine production, and NK cell proliferation [16]. NKG2D is the most well-understood NK cell stimulatory receptor [80]. It binds to MHC class I chain-related proteins A and B (MICA and MICB), which are expressed at low levels on healthy tissue and are upregulated in the presence of DNA damage or cellular transformation. NKG2D cognate ligand binding results in enhancement of NK cell cytotoxic potential. Currently, there are no clinical trials targeting NKG2 inhibitory isoforms [81]; however, there are NKG2D CAR-T cell-based therapies under clinical evaluation including CYAD-101, NKR-2, and KD-025. All are in early recruitment phases [82-87]. Similar to other receptors relevant to ICB-based therapy, NKG2 has a wide variety of roles that may contribute to tumor immunity or tumor progression in unknown ways. The results of these trials are highly anticipated as the field continues to focus on improving responses to IT in CRC. 


\subsection{Adoptive Cell Therapies}

Adoptive cell therapy, which is also known as adoptive cell transfer, cellular adoptive IT, or T cell transfer therapy, is a type of IT in which a patient's T cells are removed from their blood, expanded ex vivo, sometimes modified to enhance their anti-tumor activity, and then administered back to the patient [53]. Adoptive cell therapies include tumorinfiltrating lymphocyte (TIL) therapy, engineered T cell receptor (TCR) T cell therapy, chimeric antigen receptor T cell (CAR-T cell) therapy, and NK cell therapy $[53,88]$. ACT is highly personalized to the patient; however, it is generally expensive and difficult to manufacture. Possible side effects include a sudden increase in cytokine levels that can result in mild fever, nausea, headache, rash, rapid heartbeat, low blood pressure, or trouble breathing. Graft versus host disease and B cell aplasia are other risks that come with ACT. A rare side effect of TIL therapy is capillary leak syndrome, which could result in dangerously low blood pressure [89]. Despite these limitations and toxicities, these personalized therapies confer immune memory due to permanent modification of antitumor immune cells [56].

\subsubsection{Tumor-Infiltrating Lymphocyte Therapy}

TILs are lymphocytes that accumulate at the tumor margins or infiltrate within the tumor. These TILs are a heterogeneous population of cells that recognize tumor-associated antigens [TAAs) that are uniquely expressed or overexpressed by cancer cells. These cells can be isolated from single-cell suspensions from tumor samples collected during surgery. These tumor samples are homogenized and cultured using various protocols designed to massively expand the TILs, such as culturing them in the presence of specific cytokines or APCs, and are then reinfused into the patient [53]. It was demonstrated as early as 1986 that the adoptive cell transfer of TILs to mice bearing MC-38 colon adenocarcinoma tumors caused significant regression of liver and lung micrometastases [90]. There are currently no approved TIL therapies for CRC; however, numerous therapies are under evaluation in clinical trials [91].

\subsubsection{Engineered T Cell Therapy}

As $\mathrm{T}$ cells play a key role in mediating anti-tumor immunity, efforts have been made to genetically engineer or modify $\mathrm{T}$ cells to enhance their anti-tumor effects. Therapies developed from these efforts include TCR T cell therapy and CAR-T cell therapy. The modification of $\mathrm{T}$ cells can involve viral vector transfection using a lentivirus or retrovirus to express specific TCRs or CARs on the T cell surface. Both of these therapies are autologous, meaning they involve extraction, ex vivo modification, and re-infusion of a patient's own T cells. However, their antigen recognition mechanisms differ. TCRs use heterodimers to recognize MHC class I-presented peptides on tumor cells, while CAR-T cells use antibody fragments to directly bind to antigens on cancer cells (Figure 2). Because the peptides presented by TCRs have gone through processing by APCs, TCRs can recognize intracellular proteins, while the antigens that are recognized by CAR T cells must be expressed on the cancer cell surface [92]. Costimulatory molecules are often administered with engineered $\mathrm{T}$ cells, including CD28 or 4-1BB (CD137) [92]. Low efficacy due to a lack of tumor-specific antigens and adverse events after CAR-T treatment of patients with solid tumors necessitates new approaches including the addition of immune-activating molecules on CAR-T cells, regional administration, bispecific engagers, and optimization of CAR structure [93]. Very few clinical studies evaluating TCR T cells are underway, but one ongoing trial is investigating the use of TCRs that were cloned from neoepitope-targeting CD8+ cells in the patient's blood for treatment of solid tumors [94]. 


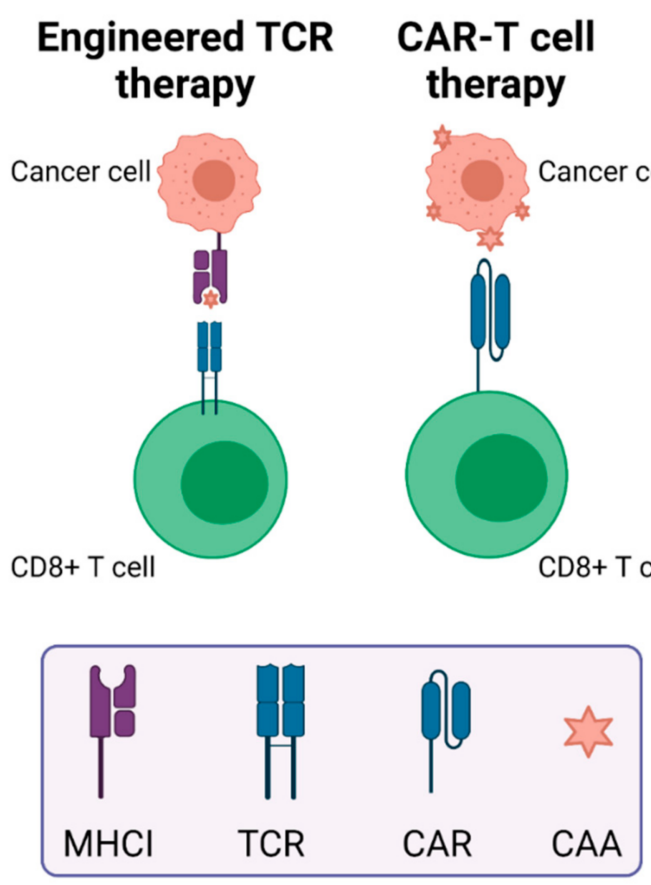

Figure 2. Engineered TCR therapy vs. CAR-T cell therapy. Engineered TCR T cell therapy involves engineering $\mathrm{T}$ cells with receptors that are specific for MHC class I-presented antigenic peptides. CAR-T cell therapy involves direct recognition of CAAs on the cancer cell surface. CAA, cancerassociated antigen; $\mathrm{CAR}$, chimeric antigen receptor; $\mathrm{MHCI}$, major histocompatibility complex class I; TCR, T cell receptor. Created in BioRender.

\subsubsection{Natural Killer Cell Therapy}

Natural killer (NK) cells are an essential component of the anti-tumor response. Similar to cytotoxic CD8+ T cells, NK cells recognize and directly kill cancer cells through the release of cytotoxic granules containing perforin and granzyme or through other pathways involving FasL/Fas. NK cells also produce IFN- $\gamma$ and TNF- $\alpha$ as well as other important anti-cancer cytokines. Due to their evident role in eliminating cancerous cells and enhancing the anti-tumor response, NK cell-based therapies have been a topic of interest in cancer therapy development. These therapies involve autologous transfusion of NK cells that have been expanded, primed, and/or modified to enhance tumor cell killing. Similar to CAR-T cell therapy, CAR-NK cell therapy involves genetic modification of NK cells to enhance their recognition of cancer cell antigens [95].

CAR-NK cells in development for treatment of CRC include those that recognize epithelial cell adhesion molecule (EpCAM/CD326), which is overexpressed in many solid tumors and upregulates oncogene expression and cell proliferation [17]. NK cells have also been modified to recognize carcinoembryonic antigen (CEA) [95], which for many years has been the only widely recommended prognostic biomarker for CRC [96]. CEA levels are expected to fall after surgical resection of the tumor [97] and overexpression may contribute to human cancer progression by inhibiting cell differentiation, apoptosis, and anoikis [28]. Preclinical evaluations have thus far demonstrated positive anti-tumor activity.

Several NK cell therapies have been translated into clinical trials, one of which is indicated for MUC1-positive solid tumors including CRC [98]. MUC-1 is aberrantly overexpressed in CRC [36] and preliminary results of this trial show promise [95]. Other trials involve combination of NK cell-based therapies with various other treatments including radiotherapy [99], cetuximab [100], bevacizumab [101], and chemotherapy [102]. 


\subsection{Monoclonal Antibodies}

mAbs used for cancer therapy are a homogenous pool of antibodies that are specific for antigens which are overexpressed in cancer cells. Such antigens are often referred to as cancer-associated antigens (CAAs). mAbs may also be used for imaging when paired with a marker such as a radionuclide [103]. Early development of $\mathrm{mAb}$ therapy involved naked $\mathrm{mAbs}$, which simply bind to a target and prevent its downstream signaling. More sophisticated approaches have been taken to improve efficacy of $\mathrm{mAb}$ therapy including the conjugation of mAbs to toxins or therapeutic agents, as well as the generation of bispecific mAbs which recognize distinct epitopes on each end of the molecule. In addition to blocking downstream signaling, IgG mAbs can induce antibody-dependent cell-mediated cytotoxicity (ADCC) via binding of the Fc receptor to immune cells [104]. Advantages of mAbs include their specificity, effectiveness across many cancer types, ease of conjugation, and low cost compared to other ITs. However, some limitations exist including an expensive target identification process, common inadequate pharmacokinetics and tissue accessibility, and development of resistance mechanisms [56].

\subsubsection{Naked Monoclonal Antibodies}

The majority of $\mathrm{mAbs}$ that are used in clinical practice to treat $\mathrm{CRC}$ are naked $\mathrm{mAbs}$. These include cetuximab (anti-EGFR), panitumumab (anti-EGFR), bevacizumab (anti-VEGF), nivolumab (anti-PD-1), pembrolizumab (anti-PD-1), and ipilimumab (anti-CTLA-4).

$m A b s$ have been developed to target EGFR, a receptor that is often overactive in $\mathrm{CRC}$ cells and triggers cell proliferation. Cetuximab is a chimeric $\mathrm{mAb}$ which contains a human constant region and a murine variable region, and is FDA-approved for $\mathrm{mCRC}$ patients who overexpress EGFR and who are refractory to or intolerant of irinotecanbased chemotherapy. Panitumumab is a human $\mathrm{mAb}$ for $\mathrm{mCRC}$ patients who overexpress EGFR and who have failed fluoropyrimidine-, oxaliplatin-, and irinotecan-containing chemotherapy regimens. Panitumumab has a higher binding affinity for EGFR, and due to the absence of murine components, has a longer half-life and causes fewer infusion reactions compared to cetuximab [18]. The overall survival of patients receiving cetuximab (10 months) and panitumumab (10.4 months) was similar in the phase III ASPECCT study, indicating their comparable efficacy (HR 0.97; 95\% CI 0.84-1.11) [2,105]. Anti-EGFR mAbs are thought to induce ADCC via binding of the Fc receptor to immune cells, though the extent of ADCC induction across EGFR inhibitors varies and the contribution of ADCC to the mechanism of cetuximab and panitumumab is questionable $[2,104]$. New antiEGFR mAbs in development such as GA201 and imgatuzumab have been glycoengineered to enhance intrinsic ADCC induction [106,107]. A majority of CRC patients receiving anti-EGFR therapy experience dermatological toxicity in the form of a skin rash. 50\% of patients receiving cetuximab for more than 6 months experience hypomagnesemia. Infusion reactions occur in $3.5-7.5 \%$ of patients [108].

VEGF is a soluble factor that stimulates the production of blood vessels, and is often overexpressed in CRC. Bevacizumab, which is FDA-approved for the treatment of mCRC [18], binds to soluble VEGF and prevents binding of this growth factor with its receptors VEGFR-1 and VEGFR-2. Both wild-type and mutated KRAS tumors, as well as both left- and right-sided tumors, seem to respond well to bevacizumab in both the firstand second-line settings [2]. Anti-EGFR and anti-VEGF mAbs have been directly compared in the clinic, revealing that cetuximab is likely more effective against left-sided, wild-type RAS tumors [2]. As a first-line therapy, cetuximab might improve the efficacy of subsequent bevacizumab therapy for these patients [109]. Side effects associated with bevacizumab, include hypertension, proteinuria, epistaxis, upper respiratory infection, anorexia, stomatitis, diarrhea or other gastrointestinal symptoms, headache, dyspnea, fatigue, and exfoliative dermatitis [110].

As discussed above, the ICB mAbs ipilimumab (+nivolumab) and pembrolizumab are approved for MSI-H mCRC tumors. 


\subsubsection{Conjugated Monoclonal Antibodies}

The feasibility and clinical efficacy of conjugated mAbs for treatment of CRC was demonstrated decades ago in a 1991 study of mCRC patients treated with either a CEA- or tumor-associated glycoprotein (TAG)-targeting mAb conjugated to iodine-13 [111]. Since then, several other studies have demonstrated that conjugated mAbs can be efficacious for treatment of CRC. Panitumumab has been conjugated to platinum agents and demonstrated excellent in vivo efficacy in reducing CRC tumor size [112]. Specific populations of cells such as stem cells, which express cell surface marker CD133, within the TME can be targeted with conjugated mAbs. Suppressed tumor growth and decreased recurrence was observed in an HCT116 xenograft model after treatment with anti-CD133 antibody-conjugated SN-38 nanoparticles [19]. HER3, a growth factor receptor that is overexpressed in CRC, has been targeted with U3-1402, a novel HER3-antibody conjugated to a topoisomerase I inhibitor. In vivo investigation of U3-1402 demonstrated tumor regression independent of KRAS status [20]. Following the success of the HER2-targeting mAb trastuzumab conjugated with the DNA topoisomerase I inhibitor deruxtecan (together known as ENHERTU) in the phase 2 DESTINY-Breast01 trial, this therapy was evaluated in several other types of solid tumors [113] including CRC (DESTINY-CRC01 [114]. Results of the DESTINY-CRC01 trial demonstrated durable responses in patients with previously treated HER2-positive mCRC (median progression-free survival 6.9 months, 95\% CI $=4.1$ months-not evaluable) [23], further supporting the use of conjugated $\mathrm{mAbs}$ in the targeted treatment of CRC in the adjuvant setting.

\subsubsection{Bispecific Antibodies}

Bispecific antibodies (bsAbs) are antibodies that recognize two distinct epitopes on either end. Bispecific antibodies can be separated into combinatorial or obligate. Combinatorial bsAbs have a function or activity that could be achieved by combining two separate mAbs whereas obligate bsAbs have a function or activity that cannot be achieved with two separate mAbs, with the latter being a more attractive format due to the potential of creating novel functionality. Obligate bsAbs create novel functions by (1) bridging cell types such as cytotoxic CD8+ T cells and cancer cells to induce T cell-mediated killing, (2) crosslinking receptors on cells to either inactivate or activate them, (3) positioning an enzyme and substrate as a cofactor mimetic, or 4) using one binding end to gain access into a restricted cellular compartment and using the other to exert a therapeutic effect, often referred to as "hijacking" or "piggybacking" [24].

Most bsAbs are T cell-engaging bsAbs (bsTCEs) that engage T cells using CD3, a cell surface protein expressed on both CD8+ and CD4+ T cells. bsTCEs have shown great preclinical efficacy. For example, a bsTCE targeting GPA33, which is expressed on $>95 \%$ of CRC tumors, was used to treat mice with colon or gastric cancer xenografts. Treatment resulted in tumor regression across MSS status [25]. bsTCEs have been developed to target guanylyl cyclase C (GUCY2C), which is also overexpressed in CRC. Treatment using GUCY2C-targeting bsTCEs demonstrated T cell-mediated killing of CRC cells in vitro and in vivo in CRC xenograft models across KRAS and BRAF status. Furthermore, combination of GUCY2C-targeting bsTCEs is enhanced when combined anti-PD-1/anti-PD-L1 treatment or anti-angiogenic therapies [27]. Treatment of CEA-expressing human CRC xenografts with a CEA/CD3-binding bsTCE induced an inflammatory response in the TME and caused tumor regression [115]. bsTCEs have also been designed to specifically target CD133+ stem cells in the TME and have shown efficacy in in vivo CRC models [116]. Development of resistance to bsTCEs may involve upregulation of checkpoint molecules PD-1/PD-L1; however, this may be overcome by combination treatment of bsTCEs with anti-PD-1 or anti-PD-L1 antibodies [24].

Mutation-associated neoantigens (MANAs) are proteins encoded by mutated cancer driver genes that have gone through proteolytic processing within the cell and are presented on the cell surface by human leukocyte antigen (HLA) molecules. TCR-mimicking antibodies directed toward these MANAs (MANAbodies) have been developed into bsTCEs 
that target mutant KRAS or TP53, two genetic alterations frequently found in CRC. These bsTCEs can recognize and kill cancer cells with very low levels of their cognate antigen in vitro and in vivo [117-119].

Gamma delta $(\gamma \delta)$ T cells are unconventional T cells that play a major role in the T cellmediated anti-tumor response despite the fact that they represent only a small fraction of the total T cell population in peripheral blood [120]. bsTCEs targeting EGFR-positive cancer cells for $\gamma \delta$ T cell-mediated death have been developed and have demonstrated efficacy in killing CRC cells while sparing EGFR+ keratinocytes, suggesting that this treatment may have a high therapeutic index in patients [24].

Some bsAbs are not $\mathrm{T}$ cell-engaging but can suppress tumors by different mechanisms. For example, vanucizumab, a bsAb targeting VEGF-A and angiopoietin-2, demonstrated acceptable tolerability and decreased tumor vascularity in a heterogeneous population of patients with solid tumors (13/42 had CRC) [31]. In a CRC xenograft model, vanucizumab in combination with chemotherapy was superior compared to the clinical standard of anti-VEGF and chemotherapy combination treatment [121]. Additionally, bsAbs have been conjugated with toxic particles, inducing both photothermal and immune-mediated killing of cancer cells in a heterotopic colorectal tumor model [122].

A disappointing phase I study investigating LY3164530, a bsAb targeting MET and EGFR, demonstrated the important limitation of bsAb fixed stoichiometry. Final results indicated limited efficacy and significant toxicity due to EGFR inhibition. EGFR inhibition causes more severe toxicity than MET inhibition, but because stoichiometry of bsAbs is fixed, it is difficult to adjust relative affinities on either end of the molecule. This indicates that targets with vastly different therapeutic indices are likely not an ideal combination for the bsAb approach [32]. Several other clinical trials are underway to investigate both obligate and combinatorial bsAbs (Table 3), for example XmAb841, a bsAb against CTLA-4 and LAG-3 either alone or in combination with pembrolizumab [123].

\subsubsection{Nanobodies}

Some limitations of mAbs for the treatment of cancer include inadequate pharmacokinetics and tissue accessibility [124]. The emerging field of nanobodies (Nbs) may solve some limitations of mAbs and their derivatives, as these single-variable domains of the camelid antibody are smaller, more stable, and have better tissue penetration compared to traditional mAbs [125]. One clinical trial involved treatment of four patients with solid tumors ( 1 of which was a CRC patient) with TAS266, a nanobody that targets death receptor 5 (DR5), a cell surface receptor that triggers apoptosis [34]. However, the trial was terminated early due to dose-limiting toxicity in three patients [125,126]. Another interesting early phase I trial is recruiting mesothelin+ CRC and ovarian cancer patients for treatment with mesothelin-targeting CAR-T cells that secrete PD-1 Nbs [127]. 
Table 3. The number of clinical trials involving various types of immunotherapy for the treatment of colorectal cancer.

\begin{tabular}{|c|c|c|c|c|c|c|c|c|c|c|c|}
\hline \multicolumn{12}{|c|}{ Number of Clinical Trials } \\
\hline & ICB & $\mathrm{ACT}$ & $\mathrm{mAb}$ & $\begin{array}{l}\text { Conj. } \\
\mathrm{Ab}\end{array}$ & bsAb & Virus & Vaccine & IFN & IL & IMiD & STING \\
\hline Completed & 31 & 8 & 67 & 3 & 3 & 3 & 46 & 11 & 7 & 2 & 0 \\
\hline Active, not recruiting & 46 & 6 & 19 & - & - & 1 & 4 & 1 & 4 & - & 0 \\
\hline Recruiting & 111 & 15 & 52 & 2 & 8 & 2 & 18 & 4 & 5 & - & 1 \\
\hline Not yet recruiting & 16 & 7 & 9 & 1 & 3 & - & 2 & 1 & - & - & 0 \\
\hline Terminated & 11 & 4 & 29 & 1 & 1 & 1 & 11 & 2 & 5 & 1 & 0 \\
\hline Withdrawn & 10 & 2 & 12 & 2 & 2 & 1 & 5 & 1 & 2 & - & 0 \\
\hline Suspended & - & 1 & - & - & - & - & 1 & - & - & - & 0 \\
\hline Unknown & 9 & 14 & 15 & - & 2 & - & 9 & 5 & 2 & 3 & 0 \\
\hline Total & 234 & 57 & 203 & 9 & 19 & 8 & 96 & 25 & 25 & 6 & 1 \\
\hline
\end{tabular}

Search terms

ICB

ACT

$\mathrm{mAb}$

Conj. $\mathrm{Ab}$

bsAb

Virus

Vaccine

IFN

IL

IMiD

STING

immune checkpoint blockade OR checkpoint blockade OR immune checkpoint inhibitor OR anti-PD-1 OR anti-pdl1 OR anti-ctla4 OR anti-lag3 OR anti-tim3 OR anti-nkg2 OR PD-1 OR pdl1 OR ctla4 OR lag3 OR tim3 OR nkg2

adoptive cell therapy OR adoptive cell transfer OR cellular adoptive immunotherapy OR t cell transfer therapy OR tumor-infiltrating lymphocyte OR engineered $t$ cell OR $t$ cell receptor therapy OR car $t$ cell OR NK cell

monoclonal antibody OR monoclonal antibodies conjugated antibody OR conjugated antibodies bispecific antibody OR bispecific antibodies oncolytic virus

vaccine

interferon

interleukin

thalidomide

sting

ClinicalTrials.gov search was conducted as follows: condition or disease = colorectal cancer; intervention/treatment = search terms above; study type = interventional. Search was performed on 30 October 2021. Some trials fall into two groups, for example many ICB therapies are mAb-based. Clinical trials involving combination treatments also may fall into two groups. ACT, adoptive cell therapy; bsAb, bispecific antibody; conj. Ab, conjugated antibody; ICB, immune checkpoint blockade; IFN, interferon; IL, interleukin; IMiD, immunomodulatory drug; mAb, monoclonal antibody.

\subsection{Oncolytic Virus Therapy}

Oncolytic viruses are viruses that selectively infect and kill or incapacitate cancer cells without harming normal cells. This selectivity is achieved through genetic engineering. There has been relatively limited clinical investigation of oncolytic viruses for treatment of CRC and no such therapies are FDA-approved [128]. One phase I/II trial evaluated a genetically engineered oncolytic herpes simplex virus (NV1020) in patients with previously treated mCRC. Researchers observed that NV1020 stabilized liver metastases and patients experienced minimal toxicity, justifying a phase II/III trial; however, this has not been initiated yet [129]. JX-594 is a vaccinia poxvirus with engineered loss of thymidine kinase, enabling its replication only in cells high levels of thymidine kinase [130]. JX-594 also contains an added GM-CSF gene, encoding a cytokine that induces DC differentiation, maturation, and function, and increases T cell activity. JX-594 did not cause dose-limiting toxicity and achieved stable disease in $67 \%(n=10)$ of pre-treated CRC patients $[5,131,132]$. Combination of JX-594 with the anti-PD-L1 antibody durvalumab demonstrated tolerability and potential efficacy in mCRC patients (median overall survival 7.5 months, CI 4.910.1) [133]. The Newcastle disease virus (NDV) is an interesting natural RNA oncolytic virus. The NDV envelope protein and other intracellular factors induce an immune response to elicit a potent anti-tumor effect in a variety of cancers including CRC. Genetic modification of NDV could enhance this tumor lysis activity or could allow NDV to act as a vector for delivery of therapeutic genes [134]. Advantages of oncolytic virus therapy include specificity, and that it may induce an "immune priming" mechanism that could be utilized to improve response to other ITs [135]. One limitation of oncolytic viruses is that the host anti-viral immune response may reduce efficacy [56]. 


\subsection{Vaccines}

Cancer vaccines, or tumor vaccines, are a type of treatment that helps the body's immune system recognize and destroy cancer cells. Treatment generally involves direct administration of cells or antigens to the patient (whole-tumor or peptide vaccines, respectively), indirect antigen delivery (viral vector), or delivery of APCs that were trained ex vivo to recognize cancer cells. Following antigen delivery, APCs process and present the peptide to CD8+ T cells, stimulating anti-tumor immunity. Adjuvants, or substances designed to enhance or direct the immune system toward a cytotoxic response, are often given in combination with the vaccine. Cancer vaccines are generally therapeutic, meaning that they are administered after the cancer has been diagnosed, as opposed to a preventative vaccine that is administered pre-diagnosis. Advantages of cancer vaccines include their specificity and personalization; however, the delivery of foreign antigens through this treatment could induce rejection [56].

\subsubsection{Whole Tumor}

Whole-tumor, or whole-tumor-cell, vaccines involve direct administration of whole tumor cells to a patient. These tumor cells can either be autologous or allogenic. In theory, whole-tumor vaccines train the immune system to recognize the entire repertoire of antigens that are present in the heterogeneous TME. Intriguingly, in preclinical CRC models, wholetumor autologous vaccines exacerbated tumor growth when delivered therapeutically [136]. Initial clinical trials with autologous whole-tumor vaccines in CRC patients were similarly unimpressive [137-139]. Besides inefficacy, limitations of autologous vaccines include the large number of tumor cells needed, restricting this therapy to more advanced-stage patients with resectable tumors [140]. In contrast to autologous vaccines, allogenic vaccines use cell lines instead of tumor cells and have demonstrated improved efficacy in patients with colon cancer $[136,140]$.

\subsubsection{Peptide}

Peptide vaccines involve administration of immunogenic cancer-associated antigens to the patient. Several CRC-associated antigens have been targeted with peptide vaccines preclinically, including ephrin type-A receptor 2 (EphA2), CEA, MUC-1, Survivin, and SART3. Though clinical evaluation has revealed that peptide vaccines can cause strong antitumor immune responses in CRC patients, no correlation with improved clinical outcome has been made thus far $[40,128]$.

\subsubsection{Viral Vector}

Viral vector vaccines use a viral vector system to deliver TAAs. Some studies suggest that vector vaccines tend to generate a higher immune response compared to peptide vaccines, but clinical trials have revealed no difference between treatment groups in terms of immune response or clinical outcomes in CRC patients [128].

\subsubsection{Dendritic Cell Therapy}

The most promising type of cancer vaccine involves vaccination with DCs, in which DCs are removed from the patient, expanded and modified ex vivo to recognize TAAs, and then re-infused back into the patient to stimulate the cytotoxic $T$ cell response [128]. The most commonly known DC therapy is Sipuleucel-T for treatment of prostate cancer, which improves survival of patients by approximately 4 months [141]. For CRC, however, results have not been comparable. A randomized phase II clinical trial utilizing an autologous tumor lysate DC vaccine induced a tumor-specific immune response in patients, but did not impact on survival compared to patients receiving the standard of care [128].

\subsection{Immune System Modulators}

Immune system modulators are proteins or compounds that induce or direct a tumorsuppressive immune reaction. These include cytokines such as interleukins and interferons 
as well as compounds such as thalidomide. Cytokines and chemokines are fundamental to immune responses including the anti-tumor immune response. On a basic level, they regulate the growth of all blood cells and aid the development of immune responses in the event of bacterial infection, viral infection, or cancer development. In recent decades, researchers have begun to uncover complex roles of cytokines that contribute to both proand anti-tumor effects that are sometimes disparate across cancer types [142-144]. Contextdependent effects of cytokines should be taken into consideration in the development of immunomodulatory therapies, making their development somewhat challenging. It is also likely that molecular features such as high PD-L1, which are often found in colorectal tumors, will counteract the anti-tumor mechanisms of immune system modulators, necessitating combination therapies. Another limitation of immune system modulators is their low specificity and risk of immediate onset cytokine response syndrome, also known as cytokine storm. Nonetheless, immune system modulators have several advantages including the fact that many are already FDA-approved, their small size which facilitates access to cancer cells, their relatively low cost, and their ability to generate a general anti-cancer immune response that may oppose development of resistance [56]. Several immune system modulators have entered clinical phases of investigation (Table 3).

\subsubsection{Interleukins}

Interleukins (ILs) are a class of cytokine that are produced primarily by leukocytes. There are currently 38 recognized interleukins with some containing multiple family members such as IL- $1 \alpha$ and IL-1 $\beta$ for an overall total of more than 60 [145]. Interleukins can have a wide variety of pro- or anti- tumor effects and many have been therapeutically targeted in CRC clinical trials including IL-2, IL-12, IL-11, IL-6, IL- $\alpha$, and IL-1 $\beta$. IL-2 and IL-12 are potent activators of NK cells and CD8+ T cells. IL-11 and IL-6 are tumor-promoting cytokines that function by various mechanisms [41]. It is well established that IL-1 $\alpha$ and IL-1 $\beta$ contribute to pro-tumor and anti-tumor mechanisms and have pleiotropic effects on immune cells, angiogenesis, cancer cell proliferation, migration, and metastasis [41,44,45], and therefore there is much controversy over whether or not they should be inhibited in cancer. Treatment of mCRC patients via activation IL-2 or IL-12, or inhibition of IL-11, IL-6, IL- $1 \alpha$, or IL- $1 \beta$, is currently under clinical investigation. Most are in combination with several other treatment regiments and evaluate efficacy enhancement of these other therapies upon addition of IL. Other ILs have been investigated preclinically, yielding results that may support clinical translation. For example, IL-33 has been shown to have potent anti-tumor activity against CRC cells that is dependent on the presence of eosinophils, which are recruited, activated, and degranulated by IL-33 [46].

\subsubsection{Interferons}

Interferons (IFNs) make up another a class of leukocyte-produced cytokines. There are three types of IFN: Type I, II, and III. Type I IFNs include 17 distinct proteins that fall into subtypes IFN $\alpha, \operatorname{IFN} \beta, \operatorname{IFN} \varepsilon, \operatorname{IFN} \kappa$ and IFN $\omega$, but only IFN $\alpha$ and IFN $\beta$ have been well studied in the context of cancer. There is only one Type II IFN, IFN- $\gamma$, and Type III IFNs include IFN $\lambda 1$, IFN $\lambda 2$ and IFN $\lambda 3$. Type I and Type III IFNs are induced by pattern recognition receptor pathways, while Type II IFN- $\gamma$ is mainly induced by certain types of mitogens or cytokines including IL-12 and IL-18 produced by T cells and NK cells [146]. The role of IFNs in cancer has largely been described as anti-tumor, though evidence suggests that in certain contexts IFNs such as IFN- $\gamma$ can be pro-tumor at certain doses [147]. As mentioned above, context should be carefully considered when developing therapeutic IFN treatments.

The role of IFN dysregulation in CRC is evidenced by the fact that single-nucleotide polymorphisms (SNPs) in the IFN I and IFN II pathways impact risk of CRC development and survival post-diagnosis [146,148]. Thus, IFNs have been developed as a target for CRC therapy. IFN- $\gamma$ is likely the most well-studied IFN for treatment of CRC, but its role in cancer is not clear $[149,150]$. IFN- $\gamma$ cross-talk with immunostimulatory M1 macrophages 
can inhibit tumor growth. Stimulation of IFN- $\gamma$ production in T regs in combination with anti-PD-1 ICB caused tumor regression in MC-38 tumor-bearing mice that were resistant to single treatment with anti-PD-1. Interestingly, because the IFN- $\gamma$ receptor is expressed at higher levels on CRC stem-like cells compared to other CRC cells, IFN- $\gamma$ treatment can selectively induce apoptosis in these cells [147].

Other preclinical studies have shown less promising results. For example, mice with CT26 colon cancer tumors exposed to IFN- $\gamma$ experienced downregulation of antigen presentation and resultant immune evasion [150]. Another study demonstrated that the tumor-suppressor gene SOCS1 mediates its anti-oncogene function through negative regulation of IFN- $\gamma[150,151]$. Not surprisingly, clinical trial results have been disappointing or inconclusive. A 1995 trial suggested inefficacy of surgical adjuvant treatment for patients with high-risk colon cancer [152]. Another study combined IFN- $\gamma$ with 5-FU and anti-VEGF therapy bevacizumab, but the specific contribution of IFN- $\gamma$ to the treatment effect was not investigated $[153,154]$. There is an ongoing trial that involves treatment with IFN- $\gamma$ and the anti-PD-1 therapy nivolumab for treatment of solid cancers including MSI-H CRC. Preliminary results from other initial clinical trials indicated that low or moderate doses of IFN- $\gamma$ were more effective than high doses [150], suggesting that dose should be carefully considered when administering treatment and interpreting study results.

\subsection{3. cGAS-STING}

The cyclic GMP-AMP synthase (cGAS) stimulator of interferon genes (STING) pathway is the primary sensor of cytosolic double stranded DNA (dsDNA) from either invading pathogens or the cell itself when it becomes cancerous or begins to die. In response to cytosolic DNA, the cGAS-STING pathway induces Type I IFNs, other inflammatory genes, and cellular senescence to inhibit the development of cancer [50]. STING expression in CRC has independent prognostic value [155] and a STING-related prognostic score may allow identification of high-risk CRC cases [156]. The STING agonist E7766 has shown promise in the preclinical setting in terms of anti-tumor activity and induction of a tumor-specific memory response in a murine metastatic liver CRC model. E7766 is currently in clinical trials for treatment of advanced solid tumors including CRC [157].

\subsubsection{Immunomodulators}

Immunomodulatory drugs (IMiDs) therapeutically modulate the immune response to provide patient benefit by various mechanisms. In the context of cancer, IMiDs usually refer to thalidomide and its analogues lenalidomide and pomalidomide. Thalidomide inhibits angiogenesis, enhances production of TNF, and stimulates NK cells. Following the discovery of its anti-angiogenic properties, thalidomide was administered to drugresistant multiple myeloma patients who subsequently experienced tumor regression [158]. Subsequent investigation of thalidomide, lenalidomide, and pomalidomide treatment in other cancer types in vitro and in vivo indicated that IMiDs bias the immune response toward anti-tumor immunity, inhibit metastasis, and alter cancer cell signaling [159]. To date, two clinical trials involving thalidomide treatment have been completed. In one of these trials, thalidomide and capecitabine were administered to $\mathrm{mCRC}$ patients and the rate and duration of disease stabilization suggested some efficacy [160].

\subsection{Targeting the Immunosuppressive TME}

Tumors with immunosuppressive TMEs are characterized by presence of certain cell types such as myeloid-derived suppressor cells (MDSCs), M2-like tumor-associated macrophages (TAMs), and T regs, and lack of CD8+ T cells. These tumors are often classified as "cold," whereas tumors with large numbers of infiltrating, active CD8+ T cells are classified as "hot." One strategy to transform a cold tumor into a hot tumor involves inhibition of immunosuppressive cell types. One clinical trial is investigating the CCR5 inhibitor Maraviroc for treatment of mCRC. CCR5 is receptor that is expressed on CRC 
cells, MDSCs, and T regs, thus its inhibition can both slow the cancer cell growth and inhibit immunosuppression in the TME [51,52].

\section{Predictive Biomarkers for Response to IT in Colorectal Cancer}

Similarly to traditional cytotoxic therapies, IT for treatment of CRC comes with risks of side effects such as autoimmunity or cytokine storm, in which the concentration of cytokines in the blood is high enough to cause harmful inflammation and immune effects [161]. As with any therapy that causes side effects, development of predictive biomarkers is a crucial step in preventing toxicity by identifying specific patient populations who are likely or unlikely to benefit from the therapy.

Currently in CRC, physicians may predict response to IT based on the genetic alterations that are present in the patient's tumor, specific characteristics of the CRC TME, and specific serum-based (liquid) biomarkers present in patient serum. Some biomarkers used to predict response to IT in CRC are based several key molecular characteristics of this disease, such as specific genetic alterations. Others have been developed based the mechanisms of IT, including neoantigen load, antigen presentation efficiency, diversity of the TCR repertoire, activity and abundance of immune cells, expression of certain receptors on immune cells or cancer cells, and/or levels of pro- and anti-tumor cytokines. Additional biomarkers have been developed that may be used to predict response to other types of anti-cancer therapy such as levels of ctDNA and presence of intratumoral microbes or circulating microbe-associated compounds. These biomarkers are summarized in Figure 3 and are explained in more detail in the following subsections. In general, predictive biomarker development has mostly focused on ICB, though each may also have predictive value for various other ITs if their overarching mechanisms are similar.

\subsection{Prediction Based on Genetic Alterations}

Three genetic alterations that are commonly found in CRC include chromosomal instability, MSI, and CpG island methylation [162]. Presence of each alteration can indicate how likely CRC patients are to respond to IT.

\subsubsection{Chromosomal Instability}

The majority of CRC cases exhibit a chromosomal instability (CIN) phenotype characterized by a progression of genetic alterations and their resultant histological changes. Common and predicable genomic alterations include the activation of proto-oncogenes $K R A S$ and BRAF and the inactivation of the tumor-suppressor genes APC and TP53. It is clear that CIN is associated with poor prognosis in multiple tumor types including CRC; however, it is currently unclear if CIN is a biomarker of response to IT $[163,164]$. Mutations in oncogenes such as KRAS and BRAF have recently been shown to impact on immunomodulation [165]. For example, KRAS-mutant patients have more $T$ regs and less activated CD4+ memory T cells as compared to KRAS wild-type patients, resulting in a more immunosuppressive TME [166]. Moreover, there are several reports linking KRAS mutations with enhanced PD-L1 expression on tumor cells, which results in reduced T cell functionality. However, there are limited data on the role of these mutations in the prediction of response to IT [167]. 


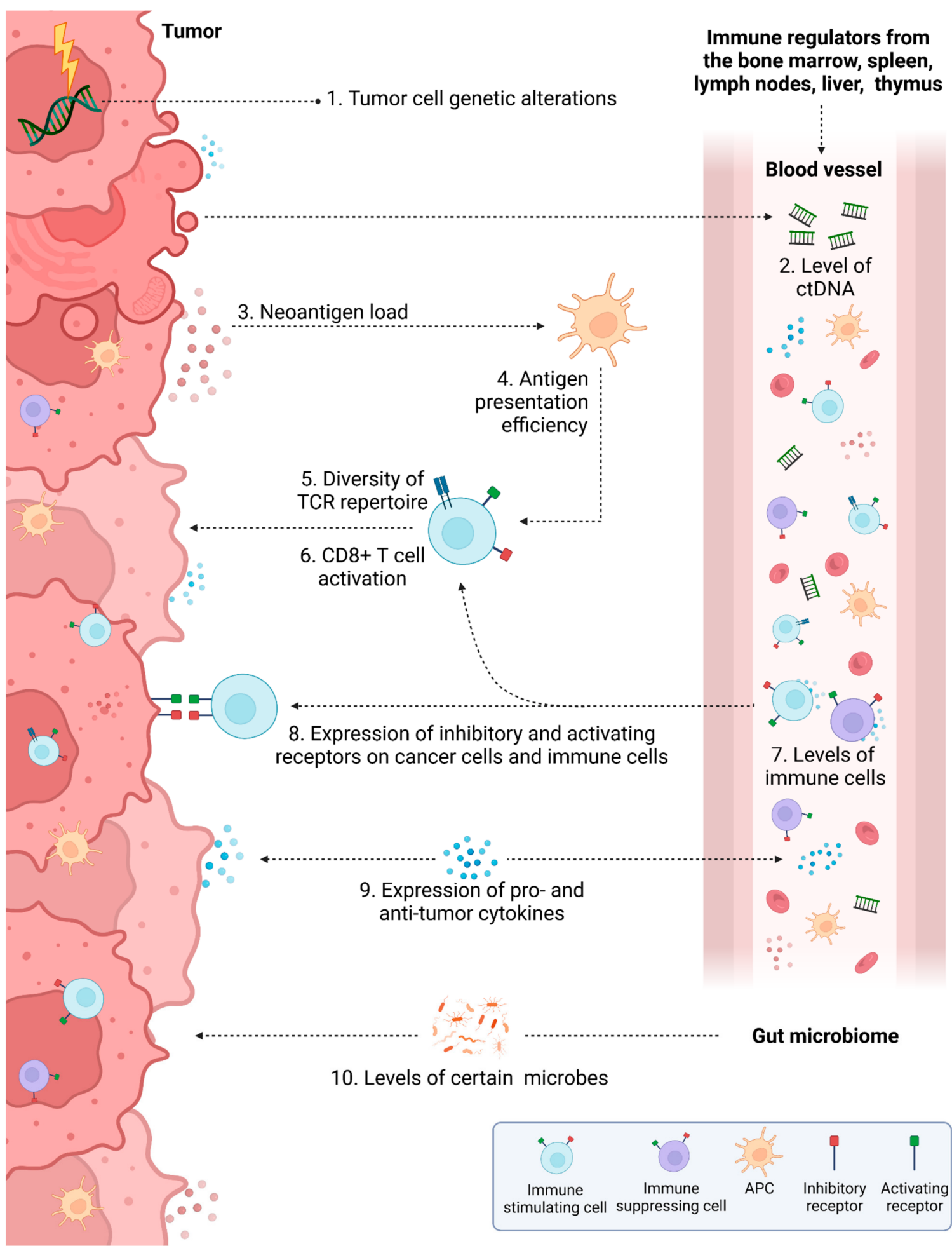

Figure 3. Key biomarkers of response to IT in CRC. (1) Certain genetic alterations in CRC cells have been associated with better response to IT. (2) A high level of ctDNA correlates with worse response to many cancer therapies including IT. (3) Neoantigen load is a key biomarker of response to several ITs including ICB. (4) High antigen presentation efficiency is associated with better response to T cell-based ITs. (5) Diversity of the TCR repertoire is associated with better response to IT. (6) A high level of CD8+ T cell activation is associated with better response to different ITs. (7) Levels of circulating and tumor-infiltrating immune cells including immune stimulatory cells (such as T cells and NK cells) and immune suppressor cells (such as T regs, MDSCs, and M2 macrophages), predict 
response to many types of IT. (8) Expression of inhibitory and activating receptors is impacts response to many types of IT, especially ICB. Circulating exosomes containing soluble receptors may also have predictive value. (9) Expression of pro- and anti-tumor cytokines by cancer cells and immune cells plays a role in response to all ITs. (10) Levels of certain gut microbes in the tumor, and levels of circulating microbe-associated compounds, may predict response to IT. APC, antigen-presenting cell; CRC, colorectal cancer; ctDNA, circulating tumor DNA; ICB, immune checkpoint blockade; IT, immunotherapy; MDSC, myeloid-derived suppressor cell; NK, natural killer; TCR. T cell receptor; T reg, T regulatory cell.

The inactivation of tumor-suppressor genes can also play a role in CRC response to IT. For example, the APC tumor-suppressor gene is involved in the cellular transition from $\mathrm{G} 1$ to $\mathrm{S}$ phase and loss of $A P C$ can result in the sustained activation of the Wnt signaling pathway and, thus, increased nuclear $\beta$-catenin [168]. It has been shown that both MSI-H and MSS CRC patients with APC biallelic mutations have decreased T cell tumor infiltration [169]. Another commonly mutated tumor-suppressor gene in CRC is TP53. The encoded protein p53 plays a role in controlling cell cycle and apoptosis. While p53 mutations in CRC classically confer resistance to conventional chemotherapies, they provide an additional benefit in the context of IT, as p53 mutated tumors often harbor an increased number of neoantigens. In contrast, wild-type p53 has been shown to enhance MHC class I peptide transport via upregulation of TAP1, the transporter associated with antigen processing [170]. Therefore, the absence of wild-type p53 in cancer cells can diminish cytotoxic T cell-mediated tumor cell death that may impact on IT outcomes in patients.

\subsubsection{Microsatellite Instability}

Approximately 15-20\% of cases of CRC exhibit the MSI-H phenotype, which is characterized by mutations in the MMR system [4]. Patients with MSI-H tumors have dMMR systems and thus, an accumulation of errors in microsatellite regions. In contrast, those MSS tumors tend to have pMMR systems, and thus a lower number of DNA replication errors. $\mathrm{dMMR}$ and the resulting MSI-H phenotype have long been considered predictors of efficacy for ICB in multiple tumor types. In CRC, MSI-H status is predictive of long-term responses to ICB [171].

\subsubsection{CpG Island Methylation}

Another common occurrence in CRC is the aberrant epigenetic regulation of gene expression. Hypermethylation occurs when methyl groups are covalently bound in regions of CG dinucleotides or CpG-rich areas of DNA in promoter regions. In instances of normal gene expression, $\mathrm{CpG}$ regions are normally maintained in the unmethylated state. Methylation of these promoter regions can lead to gene silencing in tumor-suppressor genes, which is denoted as CpG island methylator phenotype (CIMP) [162]. The presence of TILs is associated with a high degree of CIMP, along with presence of other mutations [172] which could have a positive effect on response to ITs that are dependent on T cell infiltration, such as ICB and bsTCEs. CpG island methylator phenotype-high CRC is also associated with PD-L1 status of primary tumors [173].

\subsubsection{Tumor Mutational Burden and Neoantigen Load}

In 2020, the FDA approved pembrolizumab for high tumor mutational burden (TMB-H) solid tumors based on the results of the KEYNOTE-158 study [174]. TMB is a measurement of the number of mutations per megabase of DNA in tumor cells. Typically, TMB-H CRC tumors have more immunogenic neoantigens and a higher neoantigen load. Neoantigen load is a quantification of mutations that can be targeted by T cells and is a biomarker of response to IT. Neoantigen load is correlated with the presence of TILs in both MSI-H and MSS CRC tumors [55]. 


\subsubsection{Other Specific Genetic Alterations}

Another frequently mutated signaling pathway in CRC is the PI3K/AKT pathway. Activating mutations in PIK3CA occur in 25\% of CRC cases [175]. PIK3CA mutations are associated with CD8+ T cell infiltration, PD-L1 expression, and improved IT benefit in patients with MSS CRC [176]. The PI3K/AKT signaling pathway is negatively regulated by PTEN, a phosphatase that is mutated in approximately $18 \%$ of MSI-H CRC cases [177]. CRC studies have shown that a loss of PTEN results in increased PD-L1 expression [178]. Moreover, loss of PTEN has been reported to result in decreased TIL presence and an immunosuppressive TME [179]. Another common genetic alteration in CRC is mutations in TGF $\beta$, a collection of growth factors that regulate myriad cellular processes through their interaction with TGF $\beta$ receptors [162]. TGF $\beta$ activation is predictive of poor prognosis in CRC and is predictive of ICB resistance in several tumor types $[180,181]$. The most common mechanism of activation of TGF $\beta$ signaling in CRC is due to mutations in transforming growth factor $\beta$ receptor type 2 (TGF $\beta R 2$ ), which occurs in approximately $30 \%$ of CRC cases [182]. Mutated in TGF $\beta R 2$ is predictive of resistance to ICB in non-small-cell lung cancer (NSCLC), but there are currently limited reports concerning the prognostic significance of TGF $\beta R 2$ mutations in the context of CRC [183].

\subsection{Prediction Based on the Tumor Microenvironment}

The CRC TME is comprised of tumor cells, tumor-associated cells, endothelial cells, immune cells, and the extracellular matrix, all of which can be immunostimulatory or immunosuppressive and can influence the response to IT.

\subsubsection{PD-L1 Expression}

PD-L1 is a tumor cell-expressed surface protein that is a common biomarker of response to IT across many tumor types. Tumor cells commonly overexpress PD-L1, and this overexpression is associated with poor overall survival across multiple tumor types [184]. Paradoxically, a study by Droeser et al. reported that PD-L1 expression is correlated with CD8+ T cell infiltration in MSS CRC tumors [185]. Ultimately, the value of PD-L1 alone as a predictive biomarker has limitations.

\subsubsection{Tumor-Infiltrating Lymphocytes}

The presence and function of TILs such as T cells, B cells, and NK cells can be predictive of response to IT. A positive correlation between TILs and response to ICB has been shown repeatedly in melanoma [186]. A study by Li et al. reported that a signature of high immune cell infiltration in CRC patients was correlated with increased PD-L1 expression and better prognosis as compared to CRC patients clustered in the low and medium immune infiltration groups [187]. Interestingly, in CRC, a correlation between T reg cell tumor infiltration and response to chemo-IT has also been reported [188].

\subsubsection{Immune Status of the Tumor Microenvironment}

The immune status of the TME can be broadly categorized as immune-inflamed, immune-excluded, or immune-desert. A study by Tang et al. categorized CRC patients into four groups based on the expression signatures of cancer-associated fibroblasts, MDSCs, M2-like TAMs, CD8+ T cells, and PD-L1 expression and found that classification of CRC patients into immune subtypes was a reliable predictor of prognosis. The clustering strategy developed here has great potential to guide personalized immunotherapy based on the TME [189].

\subsubsection{Diversity of T Cell Repertoires in TME}

$\mathrm{T}$ cell receptors recognize specific antigens presented by MHC class I (for CD8+ T cells) or MHC class II (for CD4+ T cells) molecules. A process called genetic recombination occurs in T cells to rearrange the DNA at three loci (TRBV, TRBD and TRBJ) to develop TCRs that are specific for certain antigens. The $\mathrm{T}$ cell repertoire refers to all of the unique TCR 
genetic rearrangements within the adaptive immune system, thus the TME T cell repertoire refers to all of the unique TCR genetic rearrangements within the TME. Not surprisingly, having a diverse TME T cell repertoire is associated with better outcomes in response to immunotherapy. This holds true when evaluating CRC patient populations specifically. In a TCR repertoire analysis of advanced CRC patients treated with a combination of five cancer peptide vaccines and oxaliplatin-based chemotherapy, high TCR diversity scores were associated with improved response [190]. A recent report suggested a significant difference in the usage of TRBV and TRBJ genes between CRC patients and healthy controls, supporting its use as an additional TCR-based predictive biomarker in CRC [191].

\subsubsection{Tumor-Associated Macrophages}

TAMs are a type of macrophage that create an immunosuppressive TME by producing immunosuppressive cytokines and growth factors, and by increasing immune checkpoint expression on immune cells. Macrophages are classified into two types: classical-activated M1 and alternate-activated M2. The conversion between these two states is called polarization. Though immunosuppressive TAMs can exhibit either polarization phenotype, it is believed that they generally are more M2-like [192]. Studies suggest that up to $80 \%$ of cancer patients, increased levels of TAMs predict worse outcomes. In CRC, however, there are conflicting findings as far as the prognostic and predictive value of TAMs [192-194] that may be clarified with investigations that make a clear distinction between macrophages with different polarization states or phenotypes. Our knowledge of the role of TAMs in the response to IT across cancer types is very limited [195]. In CRC, TAMs express PD-1 and treatment with anti-PD-1 compounds increased phagocytosis of PD-1+ TAMs. TAMs can also sequester anti-PD-1 antibodies, preventing their therapeutic binding to their target immune cell. Thus, TAMs play key roles in modulating response to immunotherapy in CRC cells but it is not clear whether their levels actually correlate with better or worse response to IT in CRC patients [196].

\subsubsection{The Gut Microbiota}

The makeup of the gut microbiome may influence responses to immunotherapy. A recent investigation using a mouse model of CRC identified intratumoral presence of the bacterial species Bifidobacterium pseudolongum, Lactobacillus johnsonii, and Olsenella as enhancers of ICB efficacy. B. pseudolongum produced inosine, which translocated systemically after ICB-induced gut barrier impairment to activate anti-tumor T cells [197]. Another study found a significantly different ratio of Prevotella/Bacteroides species between ICB responders versus nonresponders in patients with GI cancer $(n=74 ; p=0.032)$ [198]. Thus, the relative abundance of these species within the tumor could predict response to ICB but this remains to be confirmed by ongoing clinical trials [135].

\subsection{Liquid Biomarkers}

Peripheral blood offers a non-invasive source of potential biomarkers via liquid biopsies. Liquid biopsies can provide information on circulating factors such as peripheral blood cells, tumor DNA, and cytokines. Other potential liquid biomarkers that may predict responses in CRC include exosomes.

\subsubsection{Peripheral Blood Cells}

There are significant differences in the proportions of lymphocytes, white blood cells, neutrophils and MDSCs between healthy controls and patients with CRC [199]. This differential peripheral blood cellular composition has been reported as both diagnostic and prognostic in patients with CRC. Peripheral NK cells are an independent predictor of survival in patients with CRC and their prognostic value increases when combined with B cell count [200]. In a study of CRC patients with liver metastases, patients more likely to respond to CAR T therapy had lower-fold changes in their neutrophil-to-lymphocyte (NLR) ratio [201]. 


\subsubsection{Circulating Tumor DNA}

Circulating tumor DNA (ctDNA) is tumor-derived fragmented DNA found in the bloodstream that is no longer cell-associated. In a review of ninety-two clinical studies, ctDNA was demonstrated to be a reliable measure of tumor burden and response to therapy in CRC [202]. In a study of MSS CRC patients treated with combination therapy of regorafenib and PD-1 inhibitors, the authors found that ctDNA may be predictive of early therapeutic efficacy of IT in the MSS CRC patient population. Specifically, 10 patients with rising ctDNA levels or emergence of new clones 4 weeks after treatment experienced progressive disease after 2 months, whereas 3 patients with declining ctDNA experienced stable disease [65].

\subsubsection{Cytokines}

As previously mentioned, cytokines play a key role in both pro- and anti-tumor immune responses. Predictive cytokines can be secreted by either the tumor cells or immune cells. Candidate cytokine biomarkers for CRC include APRIL, BAFF, IL8 and MMP2, which are inversely correlated with immune cell infiltration and expression of CD163, a marker of M2 macrophages [203]. Another investigation revealed that IL-17A increased expression of PD-L1 on CRC cells and that inhibition of IL-17A improved the efficacy of anti-PD-1 therapy in a murine MSS CRC model [204,205]. Further investigation and validation is needed to translate use of these biomarkers into the clinic.

\subsubsection{Exosomes}

Exosomes are a membrane-bound type of extracellular vesicle, which can carry cargo such as mRNA, microRNA (miRNA), long non-coding RNA (lncRNA), protein, DNA fragments, or debris [206] and deliver this cargo to other cells, mediating various downstream signaling pathways. Extracellular vesicles contribute to tumorigenesis in many ways [206] such as by increasing the migration of fibroblasts in the TME [207]. Exosomes containing biomarkers such as PD-1 or PD-L1 predict better response to IT in melanoma and NSCLC, whereas exosomes containing hsa-miR-320b/c/d or hsa-miR-125b-5 predict worse response to IT in NSCLC. It remains to be seen if circulating exosomes predict response to IT in CRC [208].

\subsection{Other Factors Influencing Response to IT}

Factors other than molecular features of tumor and immune cells can influence patient response to IT. Sociological factors, lifestyle, and metabolic disorders such as obesity can have a profound impact as well, though this has only been minimally investigated in CRC. In other cancer types, exercise and a healthy diet promoted therapeutic benefit from ICB. Alcohol consumption decreases response rates and is associated with decreased mutational burden and antigen presentation by DCs [209-211]. Other interesting observations have been made, such as that obesity [212-216], smoking [217-221], and estrogen signaling [222,223] all contribute to higher PD-1/PD-L1 expression and thus better response to ICB in some cancers. There are little data on the relevance of these mechanisms in CRC response to IT, and it is a requisite topic of future investigation that could have great impact on the personalization of IT in the clinic [224]. One study suggested that CRC subtypes with low-level lymphocytic reactions may be vulnerable to the immunosuppression associated with smoking [225], and another study indicated that moderate intake of alcohol was inversely correlated with distal CRC [226]. These cancer-specific effects further necessitate investigation of these factors specifically in CRC.

\section{Sensitizing CRC to IT}

Development of IT for treatment of CRC has made great strides in recent decades, particularly for patients with MSI-H tumors. ICB targeting PD-1 and CTLA-4 have been approved and are often used for this subset of CRC patients in combination or with or after failure of conventional chemotherapy regimens. Despite this, a majority of CRC patients 
(85\%) have MSS tumors that do not respond well to ICB. In this section, we describe the efforts that have been made to improve response rates.

Further investigation of the transcriptomic, cytokine, and immune cell responses to IT in MSI-H versus MSS CRC are likely to reveal differences that will guide combination treatment for MSS CRC patients. For example, the extent of immune cell, especially T cell, infiltrate is much higher in MSI-H CRC tumors and may correlate with positive response to IT [227]. Enhancing immune cell infiltration in MSS tumors, perhaps by inhibiting MDSCs, may be a promising strategy to sensitize these tumors to IT.

It is currently unclear if FDA-approved ICB treatments are more effective in the neoadjuvant or adjuvant setting, or if IT should be combined with chemotherapy or targeted treatments. Improving responses to IT in CRC will involve investigating the role of treatment timing and drug combinations. An important study revealed that neoadjuvant ipilimumab combined with nivolumab resulted in a $27 \%$ response rate in MSS tumors after only 4 weeks of treatment (95\% exact CI: 8-55\%) [70], which is striking when compared to the low response rate reported by some clinical trials [2]. These results suggest that IT treatment in the neoadjuvant setting should be strongly considered for CRC patients.

One previously discussed study suggested that DCs are the major mediator of response to IT in CRC patients with MSI-H tumors. This finding supports the notion that the tumor microenvironment has profound effects on efficacy of IT and suggests co-administration of ICB with FLT3L, a DC-promoting cytokine [67,68].

Other exciting new developments could benefit both MSS and MSI-H CRC patients. Mucosal-associated invariant T (MAIT) cells are unconventional T cells that play a key role in the immune response to microbes. These cells have been most extensively studied in the context of CRC as compared to other cancer types, but still there is no consensus regarding the role they play in anti-tumor immunity. As MAIT cells are abundant in mucosal tissue such as the gut and are found in a majority of CRC tumors, elucidating this role may guide novel immunotherapies for CRC. Both agonist and antagonist molecules of the semi-invariant TCR on invariant T cells are well characterized and would ease the development of these therapies [228].

Another recent investigation determined that mutations in more than one hundred tumor-suppressor genes can prevent immune cell recognition of cancer cells in vivo. This novel insight into the role of altered tumor suppressors in immune evasion could guide novel immunotherapies which target or restore altered tumor-suppressor genes in combination with other IT [229,230].

Other work has identified cyclooxygenase (COX-2), the enzyme that produces the pro-survival and immune evasion protein prostaglandin E2 (PGE2) [231], as a promoter of colorectal tumorigenesis and MDSC immunosuppressive activity [232]. COX-2/PGE signaling is also thought to induce M2 macrophages while inhibiting $\mathrm{T}$ cell infiltration and NK cell/DC crosstalk [231]. Thus, inhibition of COX-2 may improve response to IT. Clinical trials combining PD-1 inhibitors with the COX-2 inhibitor celecoxib as neoadjuvant therapy are recruiting [231]. One trial (NCT03026140) will investigate this combination in both MSI-H and MSS CRC patients [233].

Ongoing investigation of immune escape mechanisms will continue to reveal nextgeneration IT targets. For example, investigation of the interplay of gut microbiota and IT may reveal approaches to increase abundance of immunostimulatory microbes and decrease abundance of immunosuppressive species to enhance IT efficacy [197,198,234].

Recent work has revealed that cancer cells hijack the mitochondria of immune cells via nanotubes. Inhibiting nanotube formation led to improved outcomes after anti-PD-1 therapy in a breast cancer model, and next steps should include similar investigation in colorectal cancer [235].

Other strategies involve identifying specific groups of patients within MSS CRC that are more likely to respond to treatment. One recent investigation revealed that patients with liver metastases had a lower response rate compared to patients without metastases 
(objective response rate $0 \%$ versus 19.5\%, respectively), suggesting that IT should be more seriously considered for early-stage patients [236].

\section{Discussion and Open Questions}

Significant advancements have been made in recent decades as far as development of IT for CRC patients. The FDA approval of anti-PD-1 mAbs pembrolizumab and nivolumab, and anti-CTLA-4 mAb ipilimumab has improved the lives of many CRC patients and indicates the significant anti-cancer potential of IT. However, there are numerous topics of requisite future investigation to improve clinical response rates.

It is currently unclear if FDA-approved ICB treatments are more effective in the neoadjuvant or adjuvant setting, or if IT should be combined with chemotherapy. Recent studies have revealed a possible benefit of treating patients with first-line ICB, and other trials are investigating treatment combinations. It is likely that a majority of cancer patients will receive chemotherapy before or concurrently with immunotherapy in the near future. It is well documented that conventional chemotherapy and targeted therapies have drastic effects on cytokine production and secretion across cell types including cancer cells and immune cells. These cytokines can have effects that enhance the anti-tumor activity of the drug, but could also lead to acquired resistance of cancer cells or systemic toxicity in the patient. Cytokine profiling in cancer cells treated with these drugs can guide logical combination with IT to enhance their anti-tumor effects. This has been completed in HCT-116 CRC cells [237] and MCF7 breast cancer cells [238] treated with conventional chemotherapies and in HCT-116, HT-29, and KM12C CRC cells treated with MEK, TRK, tyrosine kinase, RET, BRAF, PARP, PI3K, and GSK-3 inhibitors as well as Imipridones [239]. In HCT-116 cells treated with chemotherapies 5-FU, irinotecan, oxaliplatin, cisplatin, or clinically relevant combinations, drug-specific effects and an impact of p53 status on the modulation cytokines IL-8, ferritin, and soluble TRAIL-R2 was observed [237]. Possible tissue-specific effects were noted after treatment of breast cancer cells and CRC cells with cisplatin, oxaliplatin, and 5-FU, including enhanced downregulation IFN- $\beta$ and TRAIL and upregulation of TRAIL-R2 in the breast cancer cells [238]. This finding demonstrates that drug effects on cancer cells are likely tissue type-dependent, and emphasizes the importance of evaluating cytokine induction in the tissue of interest. Treatment of CRC cells with clinically relevant targeted treatments revealed several effects that were observed across drug treatments despite highly heterogeneous cell line mutational profiles and therapeutic mechanisms of action. These effects included downregulation of VEGF, CXCL9, and IL-8, and included upregulation of CXCL14, CCL5, and CXCL5. Other effects were more drug-class dependent [239]. Together, studies like these could support the logical combination of treatments to enhance or direct the immune system towards anti-tumor immunity in CRC.

Another area of great importance is the development and validation of predictive biomarkers of response to IT in CRC. While neoantigen load, level of tumor-infiltrating CD8+ T cells, and PD-1/PD-L1 expression are relatively reliable biomarkers, they have limited sensitivity and specificity, and are currently limited to predicting responses only to ICB. It is reasonable to predict correlation between levels of certain biomarkers and response to specific treatments based on the overarching mechanism of specific ITs. For example, it is likely that positive responses to ITs that are ultimately dependent on the action of CD8+ cytotoxic T cells (such as ICB, certain adoptive cell transfers, and cancer vaccinations) can be predicted based on the level of CD8+ T cells in the tumor. Similarly, it is reasonable to assume that response to targeted therapies depend on the expression level of that target, that NK cell-based therapies are more effective in patients who maintain high levels of NK cells, and so on. However, validation of the majority of these biomarkers remains to be completed.

Other limitations of IT include cost and development of resistance. Though insurance companies may pay for FDA-approved drugs, patient copays can be very high and can limit access to certain expensive drugs [240]. Resistance mechanisms to IT in CRC inevitably 
develop. Of highest clinical relevance is common resistance mechanisms to anti-PD-1/PDL1 and anti-CTLA-4 ICB, which include downregulation of DC recruitment, insufficient activated or tumor-specific $\mathrm{T}$ cells, downregulation of antigen presentation, downregulation of IFN- $\gamma$, exhaustion of TILs, and increased immunosuppressive cells or cytokines. New therapeutic targets and combinations are actively being investigated to overcome these resistance mechanisms [241]. Many strategies are in clinical trials, including combination treatment with multiple ICBs, combination of ICB with costimulatory checkpoint molecules, priming cold tumors with cancer vaccines, ACT or oncolytic virus treatment before or concurrently with ICB, or modulating the microbiome to increase $\mathrm{CRC}$-specific responses to ICB [135].

In conclusion, IT holds great promise to improve the lives of CRC patients. ICB treatments have been given the most attention in recent years, likely due to their recent FDA approval. ICB response rates in a majority of CRC patients are very low, necessitating the investigation of other types of IT, combination treatments, and predictive biomarkers. The results of ongoing trials that are investigating these topics are highly anticipated.

Author Contributions: Conceptualization, W.S.E.-D., L.C. and K.E.H.; investigation, W.S.E.-D., L.C. and K.E.H.; writing — original draft preparation, L.C. and K.E.H., writing — review and editing, W.S.E.D., L.C. and K.E.H.; supervision, W.S.E.-D.; project administration, W.S.E.-D.; funding acquisition, W.S.E.-D. All authors have read and agreed to the published version of the manuscript.

Funding: This work was funded by the Teymour Alireza P'98, P'00 Family Cancer Research Fund, grant number GFT640730, established by the Alireza Family.

Conflicts of Interest: The authors declare no conflict of interest.

\section{Abbreviations}

Abbreviation
5-FU
ACT
ADCC
APCs
bsAbs
bsTCEs
CAAs
CAR-T cell
CEA
cGAS
CIMP
CIN
CRC
ctDNA
CTLA-4
DCs
dMMR
DR5
dsDNA
EpCAM/CD326
EphA2
FLT3L
Gal-9
GUCY2C
HAVCR2
HLA

\section{Meaning}

5-fluorouracil

adoptive cell therapies

antibody-dependent cell-mediated cytotoxicity

antigen-presenting cells

bispecific antibodies

$\mathrm{T}$ cell-engaging bsAbs

cancer-associated antigens

chimeric antigen receptor $\mathrm{T}$ cell

carcinoembryonic antigen

cyclic GMP-AMP synthase

CpG island methylator phenotype

chromosomal instability

colorectal cancer

circulating tumor DNA

cytotoxic T-lymphocyte-associated protein 4

dendritic cells

MMR deficiency

death receptor 5

double stranded DNA

epithelial cell adhesion molecule

ephrin type-A receptor 2

Flt-3 Ligand

galectin-9

guanylyl cyclase $C$

hepatitis A virus cellular receptor 2

human leukocyte antigen

$\begin{array}{ll}\text { Abbreviation } & \text { Meaning } \\ \text { mAbs } & \text { monoclonal antibodies } \\ \text { MAIT } & \text { mucosal-associated invariant T } \\ \text { MANAs } & \text { mutation-associated neoantigens } \\ \text { mCRC } & \text { metastatic CRC } \\ \text { MDSCs } & \text { myeloid-derived suppressor cells } \\ \text { miRNA } & \text { microRNA } \\ \text { MMR } & \text { mismatch repair } \\ \text { MSI } & \text { microsatellite instable } \\ \text { MSI-H } & \text { MSI-high } \\ \text { MSS } & \text { microsatellite stable } \\ \text { Nbs } & \text { nanobodies } \\ \text { NDV } & \text { Newcastle disease virus } \\ \text { NK } & \text { natural killer } \\ \text { NKG2 } & \text { Natural Killer Group 2 } \\ \text { NLR } & \text { neutrophil-to-lymphocyte } \\ \text { NSCLC } & \text { non-small-cell lung cancer } \\ \text { PD-1 } & \text { programmed cell death protein 1 } \\ \text { PD-L1 } & \text { programmed cell death ligand 1 } \\ \text { PFS } & \text { progression-free survival } \\ \text { pMMR } & \text { proficient MMR } \\ \text { PtdSer } & \text { phosphatidyl serine } \\ \text { SNPs } & \text { single-nucleotide polymorphisms } \\ \text { STING } & \text { stimulator of interferon genes } \\ \text { STRs } & \text { short tandem repeats } \\ \text { T regs } & \text { regulatory T cells } \\ \text { TAAs } & \text { tumor-associated antigens }\end{array}$




Abbreviation
HMGB1
ICB
IFNs
ILs
IMiDs
IT

LAG-3

lncRNA

\section{Meaning}

high mobility group box 1 protein

immune checkpoint blockade

interferons

interleukins

immunomodulatory drugs

immunotherapy

lymphocyte activation gene-3

long non-coding RNA

Abbreviation
TAG
TAMs
TCR
TGF $\beta$ R2
TIL
TIM-3

TMB-H

TME

\section{Meaning}

tumor-associated glycoprotein

tumor-associated macrophages

$\mathrm{T}$ cell receptor

transforming growth factor $\beta$ receptor type 2 tumor-infiltrating lymphocyte

T cell immunoglobulin- and mucindomain-containing-3

high tumor mutational burden

tumor microenvironment

\section{References}

1. Rawla, P.; Sunkara, T.; Barsouk, A. Epidemiology of colorectal cancer: Incidence, mortality, survival, and risk factors. Prz. Gastroenterol. 2019, 14, 89-103. [CrossRef] [PubMed]

2. Xie, Y.-H.; Chen, Y.-X.; Fang, J.-Y. Comprehensive review of targeted therapy for colorectal cancer. Signal Transduct. Target Ther. 2020, 5, 22. [CrossRef] [PubMed]

3. Müller, M.F.; Ibrahim, A.E.K.; Arends, M.J. Molecular pathological classification of colorectal cancer. Virchows Arch. 2016, 469, 125-134. [CrossRef] [PubMed]

4. Nojadeh, J.N.; Sharif, S.B.; Sakhinia, E. Microsatellite instability in colorectal cancer. EXCLI J. 2018, 17, 159-168. [PubMed]

5. Tintelnot, J.; Stein, A. Immunotherapy in colorectal cancer: Available clinical evidence, challenges and novel approaches. World J. Gastroenterol. 2019, 25, 3920-3928. [CrossRef]

6. Boland, C.R.; Goel, A. Microsatellite instability in colorectal cancer. Gastroenterology 2010, 138, 2073-2087.e3. [CrossRef]

7. Berger, M.D.; Lenz, H.J. The safety of monoclonal antibodies for treatment of colorectal cancer. Expert Opin. Drug Saf. 2016, 15, 799-808. [CrossRef]

8. Golshani, G.; Zhang, Y. Advances in immunotherapy for colorectal cancer: A review. Therap. Adv. Gastroenterol. 2020, 13, 1-11. [CrossRef]

9. Marcus, L.; Lemery, S.J.; Keegan, P.; Pazdur, R. FDA Approval Summary: Pembrolizumab for the Treatment of Microsatellite Instability-High Solid Tumors. Clin. Cancer Res. 2019, 25, 3753-3758. [CrossRef]

10. Overman, M.J.; McDermott, R.; Leach, J.L.; Lonardi, S.; Lenz, H.-J.; Morse, M.A.; Desai, J.; Hill, A.; Axelson, M.; Moss, R.A.; et al. Nivolumab in patients with metastatic DNA mismatch repair-deficient or microsatellite instability-high colorectal cancer (CheckMate 142): An open-label, multicentre, phase 2 study. Lancet Oncol. 2017, 18, 1182-1191. [CrossRef]

11. Iliopoulos, D.; Kavousanaki, M.; Ioannou, M.; Boumpas, D.; Verginis, P. The negative costimulatory molecule PD-1 modulates the balance between immunity and tolerance via miR-21. Eur. J. Immunol. 2011, 41, 1754-1763. [CrossRef] [PubMed]

12. Han, Y.; Liu, D.; Li, L. PD-1/PD-L1 pathway: Current researches in cancer. Am. J. Cancer Res. 2020, 10, 727-742. [PubMed]

13. Van Coillie, S.; Wiernicki, B.; Xu, J. Molecular and Cellular Functions of CTLA-4. Adv. Exp. Med. Biol. 2020, 1248, 7-32. [PubMed]

14. Anderson, A.C.; Joller, N.; Kuchroo, V.K. Lag-3, Tim-3, and TIGIT: Co-inhibitory Receptors with Specialized Functions in Immune Regulation. Immunity 2016, 44, 989-1004. [CrossRef] [PubMed]

15. Borrego, F.; Masilamani, M.; Marusina, A.I.; Tang, X.; Coligan, J.E. The CD94/NKG2 family of receptors: From molecules and cells to clinical relevance. Immunol. Res. 2006, 35, 263-278. [CrossRef]

16. Lanier, L.L. Up on the tightrope: Natural killer cell activation and inhibition. Nat. Immunol. 2008, 9, 495-502. [CrossRef] [PubMed]

17. Zhang, Q.; Zhang, H.; Ding, J.; Liu, H.; Li, H.; Lu, M.; Miao, Y.; Li, L.; Zheng, J. Combination Therapy with EpCAM-CAR-NK-92 Cells and Regorafenib against Human Colorectal Cancer Models. J. Immunol. Res. 2018, 2018, 4263520. [CrossRef]

18. Goodin, S. Development of monoclonal antibodies for the treatment of colorectal cancer. Am. J. Health Syst. Pharm. 2008, 65 (Suppl. 4), S3-S7. [CrossRef]

19. Ning, S.-T.; Lee, S.-Y.; Wei, M.-F.; Peng, C.-L.; Lin, S.Y.-F.; Tsai, M.-H.; Lee, P.-C.; Shih, Y.-H.; Lin, C.-Y.; Luo, T.-Y.; et al. Targeting Colorectal Cancer Stem-Like Cells with Anti-CD133 Antibody-Conjugated SN-38 Nanoparticles. ACS Appl. Mater. Interfaces 2016, 8, 17793-17804. [CrossRef]

20. Koganemaru, S.; Kuboki, Y.; Koga, Y.; Kojima, T.; Yamauchi, M.; Maeda, N.; Kagari, T.; Hirotani, K.; Yasunaga, M.; Matsumura, Y.; et al. U3-1402, a Novel HER3-Targeting Antibody-Drug Conjugate, for the Treatment of Colorectal Cancer. Mol. Cancer Ther. 2019, 18, 2043-2050. [CrossRef]

21. Lédel, F.; Stenstedt, K.; Hallström, M.; Ragnhammar, P.; Edler, D. HER3 expression in primary colorectal cancer including corresponding metastases in lymph node and liver. Acta Oncol. 2015, 54, 480-486. [CrossRef] [PubMed]

22. Takegawa, N.; Yonesaka, K. HER2 as an Emerging Oncotarget for Colorectal Cancer Treatment After Failure of Anti-Epidermal Growth Factor Receptor Therapy. Clin. Colorectal Cancer 2017, 16, 247-251. [CrossRef] [PubMed]

23. Stenger, M. Trastuzumab Deruxtecan-nxki in HER2-Positive Metastatic Colorectal Cancer: DESTINY-CRC01. 2021. Available online: https: / / ascopost.com/news/may-2021/trastuzumab-deruxtecan-nxki-in-her2-positive-metastatic-colorectal-cancerdestiny-crc01/ (accessed on 10 July 2021). 
24. Labrijn, A.F.; Janmaat, M.L.; Reichert, J.M.; Parren, P.W.H.I. Bispecific antibodies: A mechanistic review of the pipeline. Nat. Rev. Drug Discov. 2019, 18, 585-608. [CrossRef] [PubMed]

25. Wu, Z.; Guo, H.-F.; Xu, H.; Cheung, N.-K.V. Development of a Tetravalent Anti-GPA33/Anti-CD3 Bispecific Antibody for Colorectal Cancers. Mol. Cancer Ther. 2018, 17, 2164-2175. [CrossRef]

26. Rageul, J.; Mottier, S.; Jarry, A.; Shah, Y.; Théoleyre, S.; Masson, D.; Gonzalez, F.J.; Laboisse, C.L.; Denis, M.G. KLF4-dependent, PPARgamma-induced expression of GPA33 in colon cancer cell lines. Int. J. Cancer 2009, 125, 2802-2809. [CrossRef]

27. Mathur, D.; Root, A.R.; Bugaj-Gaweda, B.; Bisulco, S.; Tan, X.; Fang, W.; Kearney, J.C.; Lucas, J.; Guffroy, M.; Golas, J.; et al. A Novel GUCY2C-CD3 T-Cell Engaging Bispecific Construct (PF-07062119) for the Treatment of Gastrointestinal Cancers. Clin. Cancer Res. 2020, 26, 2188-2202. [CrossRef]

28. Shiozawa, M.; Chang, C.-H.; Huang, Y.-C.; Chen, Y.-C.; Chi, M.-S.; Hao, H.-C.; Chang, Y.-C.; Takeda, S.; Chi, K.-H.; Wang, Y.-S. Pharmacologically upregulated carcinoembryonic antigen-expression enhances the cytolytic activity of genetically-modified chimeric antigen receptor NK-92MI against colorectal cancer cells. BMC Immunol. 2018, 19, 27. [CrossRef]

29. Zhu, G.; Pe, L.; Xia, H.; Tang, Q.; Bi, F. Role of oncogenic KRAS in the prognosis, diagnosis and treatment of colorectal cancer. Mol. Cancer 2021, 20, 143. [CrossRef]

30. Michel, M.; Kaps, L.; Maderer, A.; Galle, P.; Moehler, M. The Role of p53 Dysfunction in Colorectal Cancer and Its Implication for Therapy. Cancers 2021, 13, 2296. [CrossRef]

31. Hidalgo, M.; Martinez-Garcia, M.; Le Tourneau, C.; Massard, C.; Garralda, E.; Boni, V.; Taus, A.; Albanell, J.; Sablin, M.-P.; Altet, M.; et al. First-in-Human Phase I Study of Single-agent Vanucizumab, A First-in-Class Bispecific Anti-Angiopoietin-2/Anti-VEGF-A Antibody, in Adult Patients with Advanced Solid Tumors. Clin. Cancer Res. 2018, 24, 1536-1545. [CrossRef]

32. Patnaik, A.; Gordon, M.; Tsai, F.; Papadopoulous, K.; Rasco, D.; Beeram, S.M.; Fu, S.; Janku, F.; Hynes, S.M.; Gundala, S.R.; et al. A phase I study of LY3164530, a bispecific antibody targeting MET and EGFR, in patients with advanced or metastatic cancer. Cancer Chemother. Pharmacol. 2018, 82, 407-418. [CrossRef] [PubMed]

33. Safaie Qamsari, E.; Safaie Ghaderi, S.; Zarei, B.; Dorostkar, R.; Bagheri, S.; Jadidi-Niaragh, F.; Somi, M.H.; Yousefi, M. The c-Met receptor: Implication for targeted therapies in colorectal cancer. Tumour Biol. 2017, 39, 1-13. [CrossRef] [PubMed]

34. Wu, G.S.; Burns, T.F.; McDonald, E.R., 3rd; Jiang, W.; Meng, R.; Krantz, I.D.; Kao, G.; Gan, D.D.; Zhou, J.Y.; Muschel, R.; et al. KILLER/DR5 is a DNA damage-inducible p53-regulated death receptor gene. Nat. Genet. 1997, 17, 141-143. [CrossRef] [PubMed]

35. Xiao, T.; Xiao, Y.; Wang, W.; Tang, Y.Y.; Xiao, Z.; Su, M. Targeting EphA2 in cancer. J. Hematol. Oncol. 2020, 13, 114. [CrossRef] [PubMed]

36. Takahashi, H.; Jin, C.; Rajabi, H.; Pitroda, S.P.; Alam, M.; Ahmad, R.; Raina, D.; Hasegawa, M.; Suzuki, Y.; Tagde, A.; et al. MUC1-C activates the TAK1 inflammatory pathway in colon cancer. Oncogene 2015, 34, 5187-5197. [CrossRef] [PubMed]

37. Mita, A.C.; Mita, M.M.; Nawrocki, S.T.; Giles, F.J. Survivin: Key regulator of mitosis and apoptosis and novel target for cancer therapeutics. Clin. Cancer Res. 2008, 14, 5000-5005. [CrossRef]

38. Cai, Y.; Ma, W.; Huang, X.; Cao, L.; Li, H.; Jiang, Y.; Lu, N.; Yin, Y. Effect of survivin on tumor growth of colorectal cancer in vivo. Int. J. Clin. Exp. Pathol. 2015, 8, 13267-13672.

39. Sherman, E.J.; Mitchell, D.C.; Garner, A.L. The RNA-binding protein SART3 promotes miR-34a biogenesis and G(1) cell cycle arrest in lung cancer cells. J Biol Chem. 2019, 294, 17188-17196. [CrossRef]

40. Bartnik, A.; Nirmal, A.J.; Yang, S.Y. Peptide Vaccine Therapy in Colorectal Cancer. Vaccines 2012, 1, 1-16. [CrossRef]

41. Briukhovetska, D.; Dörr, J.; Endres, S.; Libby, P.; Dinarello, C.A.; Kobold, S. Interleukins in cancer: From biology to therapy. Nat. Rev. Cancer 2021, 21, 481-499. [CrossRef]

42. Reichert, T.E.; Watkins, S.; Stanson, J.; Johnson, J.T.; Whiteside, T.L. Endogenous IL-2 in cancer cells: A marker of cellular proliferation. J. Histochem. Cytochem. 1998, 46, 603-611. [CrossRef] [PubMed]

43. Polin, R.A.; Abman, S.H.; Rowitch, D.; Benitz, W.E. Fetal and Neonatal Physiology, 5th ed.; Elsevier: Philadelphia, PA, USA, 2017.

44. Rébé, C.; Ghiringhelli, F. Interleukin-1 $\beta$ and Cancer. Cancers 2020, 12, 1791. [CrossRef] [PubMed]

45. Baker, K.J.; Houston, A.; Brint, E. IL-1 Family Members in Cancer; Two Sides to Every Story. Front. Immunol. 2019, 10, 1197. [CrossRef] [PubMed]

46. Kienzl, M.; Hasenoehrl, C.; Valadez-Cosmes, P.; Maitz, K.; Sarsembayeva, A.; Sturm, E.; Heinemann, A.; Karg, I.J.; Schicho, R. IL-33 reduces tumor growth in models of colorectal cancer with the help of eosinophils. Oncoimmunology 2020, 9, 1776059. [CrossRef]

47. Griesenauer, B.; Paczesny, S. The ST2/IL-33 Axis in Immune Cells during Inflammatory Diseases. Front. Immunol. 2017, 8, 475. [CrossRef]

48. Castro, F.; Cardoso, A.P.; Gonçalves, R.M.; Serre, K.; Oliveira, M.J. Interferon-Gamma at the Crossroads of Tumor Immune Surveillance or Evasion. Front. Immunol. 2018, 9, 847. [CrossRef]

49. Zhu, Y.; An, X.; Zhang, X.; Qiao, Y.; Zheng, T.; Li, X. STING: A master regulator in the cancer-immunity cycle. Mol. Cancer 2019, 18, 152. [CrossRef]

50. Jiang, M.; Chen, P.; Wang, L.; Li, W.; Chen, B.; Liu, Y.; Wang, H.; Zhao, S.; Ye, L.; He, Y.; et al. cGAS-STING, an important pathway in cancer immunotherapy. J. Hematol. Oncol. 2020, 13, 81. [CrossRef]

51. CCR5-blockade in Metastatic Colorectal Cancer. Available online: https:/ /ClinicalTrials.gov/show /NCT01736813 (accessed on 11 October 2021). 
52. Mukaida, N. CCR5 antagonist, an ally to fight against metastatic colorectal cancer. Transl. Cancer Res. 2016, 5, S309-S312. [CrossRef]

53. Fan, J.; Shang, D.; Han, B.; Song, J.; Chen, H.; Yang, J.-M. Adoptive Cell Transfer: Is it a Promising Immunotherapy for Colorectal Cancer? Theranostics 2018, 8, 5784-5800. [CrossRef]

54. Pardoll, D.M. The blockade of immune checkpoints in cancer immunotherapy. Nat. Rev. Cancer 2012, 12, 252-264. [CrossRef] [PubMed]

55. Overman, M.J.; Ernstoff, M.S.; Morse, M.A. Where We Stand With Immunotherapy in Colorectal Cancer: Deficient Mismatch Repair, Proficient Mismatch Repair, and Toxicity Management. Am. Soc. Clin. Oncol. Educ. Book 2018, 38, 239-247. [CrossRef] [PubMed]

56. Johdi, N.A.; Sukor, N.K. Colorectal Cancer Immunotherapy: Options and Strategies. Front. Immunol. 2020, 11, 1624. [CrossRef] [PubMed]

57. FDA Approves First-Line Immunotherapy for Patients with MSI-H/dMMR Metastatic Colorectal Cancer. Available online: https:/ / www.fda.gov/news-events / press-announcements/fda-approves-first-line-immunotherapy-patients-msi-hdmmrmetastatic-colorectal-cancer (accessed on 11 October 2021).

58. Administration USFaD. FDA Grants Nivolumab Accelerated Approval for MSI-H or dMMR Colorectal Cancer. Available online: https:/ / www.fda.gov/drugs/resources-information-approved-drugs/fda-grants-nivolumab-accelerated-approvalmsi-h-or-dmmr-colorectal-cancer (accessed on 11 October 2021).

59. Shiu, K.-K.; Andre, T.; Kim, T.W.; Jensen, B.V.; Jensen, L.H.; Punt, C.J.A.; Smith, D.M.; Garcia-Carbonero, R.; Benavides, M.; Gibbs, P.; et al. KEYNOTE-177: Phase III randomized study of pembrolizumab versus chemotherapy for microsatellite instability-high advanced colorectal cancer. J. Clin. Oncol. 2021, 39 (Suppl. 3), 6. [CrossRef]

60. André, F.D.A.; Shiu, K.-K.; Kim, T.W.; Jensen, B.V.; Jensen, L.H.; Punt, C.; Smith, D.; Garcia-Carbonero, R.; Benavides, M.; Gibbs, P.; et al. Pembrolizumab in Microsatellite-Instability-High Advanced Colorectal Cancer. N. Engl. J. Med. 2020, 383, $2207-2218$. [CrossRef]

61. Hu, H.; Kang, L.; Zhang, J.; Wu, Z.; Wang, H.; Huang, M.; Lan, P.; Wu, X.; Wang, C.; Cao, W.; et al. Neoadjuvant PD-1 blockade with toripalimab, with or without celecoxib, in mismatch repair-deficient or microsatellite instability-high, locally advanced, colorectal cancer (PICC): A single-centre, parallel-group, non-comparative, randomised, phase 2 trial. Lancet Gastroenterol. Hepatol. 2021, 7, 38-48. [CrossRef]

62. Assessing Adjuvant Immunotherapy for MSI-H Colorectal Cancer. 2018. Available online: https://dailynews.ascopubs.org/do/ 10.5555/ADN.18.190032/full/ (accessed on 11 October 2021).

63. Hirano, H.; Takashima, A.; Hamaguchi, T.; Shida, D.; Kanemitsu, Y. Current status and perspectives of immune checkpoint inhibitors for colorectal cancer. Jpn. J. Clin. Oncol. 2020, 51, 10-19. [CrossRef]

64. Fukuoka, S.; Hara, H.; Takahashi, N.; Kojima, T.; Kawazoe, A.; Asayama, M.; Yoshii, T.; Kotani, D.; Tamura, H.; Mikamoto, Y.; et al. Regorafenib Plus Nivolumab in Patients With Advanced Gastric or Colorectal Cancer: An Open-Label, Dose-Escalation, and Dose-Expansion Phase Ib Trial (REGONIVO, EPOC1603). J. Clin. Oncol. 2020, 38, 2053-2061. [CrossRef]

65. Wang, C.; Chevalier, D.; Saluja, J.; Sandhu, J.; Lau, C.; Fakih, M. Regorafenib and Nivolumab or Pembrolizumab Combination and Circulating Tumor DNA Response Assessment in Refractory Microsatellite Stable Colorectal Cancer. Oncologist 2020, 25, e1188-e1194. [CrossRef]

66. Bocobo, A.G.; Wang, R.; Behr, S.; Carnevale, J.C.; Cinar, P.; Collisson, E.A.; Fong, L.; Kidder, W.A.; Ko, A.H.; Kolli, K.P.; et al. Phase II study of pembrolizumab plus capecitabine and bevacizumab in microsatellite stable (MSS) metastatic colorectal cancer (mCRC): Interim analysis. J. Clin. Oncol. 2021, 39 (Suppl. 3), 77. [CrossRef]

67. Research, N.C.F.C. Beating Colorectal Cancer's Immunotherapy Resistance. Available online: https://news.harvard.edu/gazette/ story/2021/10/new-way-to-overcome-colorectal-cancers-resistance-to-immune-response/ (accessed on 11 October 2021).

68. Hospital, M.G. Research Points to a Strategy for Overcoming Colorectal Cancers' Immunotherapy Resistance. Available online: https:/ / medicalxpress.com/news/2021-10-strategy-colorectal-cancers-immunotherapy-resistance.html (accessed on 11 October 2021).

69. Sobhani, N.; Tardiel-Cyril, D.R.; Davtyan, A.; Generali, D.; Roudi, R.; Li, Y. CTLA-4 in Regulatory T Cells for Cancer Immunotherapy. Cancers 2021, 13, 1440. [CrossRef] [PubMed]

70. Chalabi, M.; Fanchi, L.F.; Dijkstra, K.K.; Berg, J.G.V.D.; Aalbers, A.G.; Sikorska, K.; Lopez-Yurda, M.; Grootscholten, C.; Beets, G.L.; Snaebjornsson, P.; et al. Neoadjuvant immunotherapy leads to pathological responses in MMR-proficient and MMR-deficient early-stage colon cancers. Nat. Med. 2020, 26, 566-576. [CrossRef] [PubMed]

71. An Investigational Immuno-therapy Study of Nivolumab, and Nivolumab in Combination With Other Anti-cancer Drugs, in Colon Cancer That Has Come Back or Has Spread. Available online: https:/ / clinicaltrials.gov/ct2/show/NCT02060188 (accessed on 11 October 2021)

72. Study of Nivolumab and Relatlimab in Patients With Microsatellite Stable (MSS) Advanced Colorectal Cancer. Available online: https: / / clinicaltrials.gov/ct2/show / NCT03642067 (accessed on 11 October 2021).

73. Study of TSR-033 With an Anti-programmed Cell Death-1 Receptor (PD-1) in Participants With Advanced Solid Tumors. Available online: https:/ / clinicaltrials.gov/ct2/show / NCT03250832 (accessed on 11 October 2021).

74. Huang, Y.-H.; Zhu, C.; Kondo, Y.; Anderson, A.C.; Gandhi, A.; Russell, A.F.; Dougan, S.K.; Petersen, B.-S.; Melum, E.; Pertel, T.; et al. CEACAM1 regulates TIM-3-mediated tolerance and exhaustion. Nature 2015, 517, 386-390. [CrossRef] 
75. Smith, C.M.; Li, A.; Krishnamurthy, N.; Lemmon, M.A. Phosphatidylserine binding directly regulates TIM-3 function. Biochem. J. 2021, 478, 3331-3349. [CrossRef] [PubMed]

76. Wolf, Y.; Anderson, A.C.; Kuchroo, V.C. TIM3 comes of age as an inhibitory receptor. Nat. Rev. Immunol. 2020, $20,173-185$. [CrossRef]

77. Yang, R.; Sun, L.; Li, C.-F.; Wang, Y.-H.; Yao, J.; Li, H.; Yan, M.; Chang, W.-C.; Hsu, J.-M.; Cha, J.-H.; et al. Galectin-9 interacts with PD-1 and TIM-3 to regulate T cell death and is a target for cancer immunotherapy. Nat. Commun. 2021, 12, 832. [CrossRef]

78. A Study of TSR-022 in Participants With Advanced Solid Tumors (AMBER). Available online: https://clinicaltrials.gov/ct2 / show / NCT02817633 (accessed on 11 October 2021).

79. Sun, R.; Huang, H.; Wang, X.; Zhang, Y.; Zheng, X.; Wei, H. Up-regulation of NKG2F receptor, a functionally unknown killer receptor, of human natural killer cells by interleukin-2 and interleukin-15. Oncol. Rep. 2010, 24, 1043-1048. [CrossRef]

80. Xiao, L.; Cen, D.; Gan, H.; Sun, Y.; Huang, N.; Xiong, H.; Jin, Q.; Su, L.; Wang, K.; Yan, G.; et al. Adoptive Transfer of NKG2D CAR mRNA-Engineered Natural Killer Cells in Colorectal Cancer Patients. Mol. Ther. 2019, 27, 1114-1125. [CrossRef]

81. NKG2 I Colorectal Cancer: ClinicalTrials.gov. Available online: https://clinicaltrials.gov/ct2/results?cond=Colorectal+Cancer+ \&term $=$ NKG2\&cntry $=\&$ state $=\&$ city $=\&$ dist $=($ accessed on 11 October 2021).

82. alloSHRINK - Standard cHemotherapy Regimen and Immunotherapy With Allogeneic NKG2D-based CYAD-101 Chimeric Antigen Receptor T-cells. Available online: https:/ /ClinicalTrials.gov/show/NCT03692429 (accessed on 11 October 2021).

83. Dose Escalation and Dose Expansion Phase I Study to Assess the Safety and Clinical Activity of Multiple Doses of NKR-2 Administered Concurrently With FOLFOX in Colorectal Cancer With Potentially Resectable Liver Metastases. Available online: https: / ClinicalTrials.gov/show / NCT03310008 (accessed on 11 October 2021).

84. Haplo Allogeneic NKG2DL-targeting Chimeric Antigen Receptor-grafted $\gamma \delta \mathrm{T}$ Cells for Relapsed or Refractory Solid Tumour. Available online: https: / ClinicalTrials.gov/show / NCT04107142 (accessed on 11 October 2021).

85. Hepatic Transarterial Administrations of NKR-2 in Patients With Unresectable Liver Metastases From Colorectal Cancer. Available online: https: / / ClinicalTrials.gov/show / NCT03370198 (accessed on 11 October 2021).

86. NKG2D CAR-T(KD-025) in the Treatment of Relapsed or Refractory NKG2DL+ Tumors. Available online: https:/ ClinicalTrials gov/show/NCT04550663 (accessed on 11 October 2021).

87. Phase $1 \mathrm{~b}$ Study to Evaluate the Addition of a Pembrolizumab Treatment After Treatment With CYAD-101 With a FOLFOX Preconditioning in Metastatic Colorectal Cancer Patients. Available online: https://ClinicalTrials.gov/show/NCT04991948 (accessed on 11 October 2021).

88. Adoptive Cell Transfer: National Cancer Institute. Available online: https://www.cancer.gov/publications/dictionaries/cancerterms / def/adoptive-cell-transfer (accessed on 11 October 2021).

89. T-cell Transfer Therapy National Cancer Institute. 2020. Available online: https://www.cancer.gov/about-cancer/treatment/ types/immunotherapy/t-cell-transfer-therapy (accessed on 11 October 2021).

90. Rosenberg, S.A.; Spiess, P.; Lafreniere, R. A new approach to the adoptive immunotherapy of cancer with tumor-infiltrating lymphocytes. Science 1986, 233, 1318-1321. [CrossRef]

91. Tumor Infiltrating Lymphocyte I Colorectal Cancer: ClinicalTrials.gov. Available online: https://clinicaltrials.gov/ct2/results? cond=Colorectal+Cancer\&term=tumor+infiltrating+lymphocyte\&cntry=\&state=\&city=\&dist= (accessed on 11 October 2021).

92. Zhao, L.; Cao, Y.J. Engineered T Cell Therapy for Cancer in the Clinic. Front. Immunol. 2019, 10, 2250. [CrossRef]

93. Li, H.; Yang, C.; Cheng, H.; Huang, S.; Zheng, Y. CAR-T cells for Colorectal Cancer: Target-selection and strategies for improved activity and safety. J. Cancer 2021, 12, 1804-1814. [CrossRef] [PubMed]

94. Chmielowski, B.; Ejadi, S.; Funke, R.; Stallings-Schmitt, T.; Denker, M.; Walter Frolich, M.; Franzusoff, A.J.; Abedi, M.; Cristea, M.C. A phase Ia/Ib, open-label first-in-human study of the safety, tolerability, and feasibility of gene-edited autologous NeoTCR-T cells (NeoTCR-P1) administered to patients with locally advanced or metastatic solid tumors. J. Clin. Oncol. 2020, 38 (Suppl. 15), TPS3151. [CrossRef]

95. Liu, S.; Galat, V.; Galat, Y.; Lee, Y.K.A.; Wainwright, D.; Wu, J. NK cell-based cancer immunotherapy: From basic biology to clinical development. J. Hematol. Oncol. 2021, 14, 7. [CrossRef] [PubMed]

96. Hermunen, K.; Soveri, L.-M.; Boisen, M.K.; Mustonen, H.K.; Dehlendorff, C.; Haglund, C.H.; Johansen, J.S.; Osterlund, P. Postoperative serum CA19-9, YKL-40, CRP and IL-6 in combination with CEA as prognostic markers for recurrence and survival in colorectal cancer. Acta Oncol. 2020, 59, 1416-1423. [CrossRef] [PubMed]

97. Campos-Da-Paz, M.; Dórea, J.G.; Galdino, A.S.; Lacava, Z.G.M.; Santos, M.D.F.M.A. Carcinoembryonic Antigen (CEA) and Hepatic Metastasis in Colorectal Cancer: Update on Biomarker for Clinical and Biotechnological Approaches. Recent Pat. Biotechnol. 2018, 12, 269-279. [CrossRef] [PubMed]

98. CAR-pNK Cell Immunotherapy in MUC1 Positive Relapsed or Refractory Solid Tumor. Available online: https:/ ClinicalTrials gov/show / NCT02839954 (accessed on 11 October 2021).

99. Radiofrquency Ablation Combined With Cytokine-induced Killer Cells for Colorectal Cancer Liver Metastases. Available online: https:/ /ClinicalTrials.gov/show / NCT02419677 (accessed on 11 October 2021).

100. A Phase Ib Study of Immunotherapy with Ex Vivo Pre-Activated and Expanded Cb-Nk Cells in Combination with Cetuximab, in Colorectal Cancer Patients with Minimal Residual Disease (Mrd). Available online: https://ClinicalTrials.gov/show /NCT05040 568 (accessed on 11 October 2021). 
101. The Study of CIK Plus S-1 and Bevacizumab as Maintenance Treatment for Patients With Advanced Colorectal Cancer. Available online: https: / / ClinicalTrials.gov/show / NCT02487992 (accessed on 11 October 2021).

102. Chemotherapy Combined With CIK Treating Colon Cancer. Available online: https://ClinicalTrials.gov/show /NCT03084809 (accessed on 11 October 2021).

103. Touchefeu, Y.; Bailly, C.; Frampas, E.; Eugène, T.; Rousseau, C.; Bourgeois, M.; Bossard, C.; Faivre-Chauvet, A.; Rauscher, A.; Masson, D.; et al. Promising clinical performance of pretargeted immuno-PET with anti-CEA bispecific antibody and gallium68-labelled IMP-288 peptide for imaging colorectal cancer metastases: A pilot study. Eur. J. Nucl. Med. Mol. Imaging 2021, 48, 874-882. [CrossRef] [PubMed]

104. Baysal, H.; De Pauw, I.; Zaryouh, H.; Peeters, M.; Vermorken, J.B.; Lardon, F.; De Waele, J.; Wouters, A. The Right Partner in Crime: Unlocking the Potential of the Anti-EGFR Antibody Cetuximab via Combination With Natural Killer Cell Chartering Immunotherapeutic Strategies. Front. Immunol. 2021, 12, 737311. [CrossRef] [PubMed]

105. Price, T.J.; Peeters, M.; Kim, T.W.; Li, J.; Cascinu, S.; Ruff, P.; Suresh, A.S.; Thomas, A.; Tjulandin, S.; Zhang, K.; et al. Panitumumab versus cetuximab in patients with chemotherapy-refractory wild-type KRAS exon 2 metastatic colorectal cancer (ASPECCT): A randomised, multicentre, open-label, non-inferiority phase 3 study. Lancet Oncol. 2014, 15, 569-579. [CrossRef]

106. Kol, A.; Van Scheltinga, A.T.; Pool, M.; Gerdes, C.; De Vries, E.; De Jong, S. ADCC responses and blocking of EGFR-mediated signaling and cell growth by combining the anti-EGFR antibodies imgatuzumab and cetuximab in NSCLC cells. Oncotarget 2017, 8, 45432-45446. [CrossRef] [PubMed]

107. Oppenheim, D.E.; Spreafico, R.; Etuk, A.; Malone, D.; Amofah, E.; Peña-Murillo, C.; Murray, T.; McLaughlin, L.; Choi, B.S.; Allan, S.; et al. Glyco-engineered anti-EGFR mAb elicits ADCC by NK cells from colorectal cancer patients irrespective of chemotherapy. Br. J. Cancer 2014, 110, 1221-1227. [CrossRef] [PubMed]

108. Fakih, M.; Vincent, M. Adverse events associated with anti-EGFR therapies for the treatment of metastatic colorectal cancer. Curr. Oncol. 2010, 17 (Suppl. 1), S18-S30. [CrossRef] [PubMed]

109. Liu, S.; Jiang, C.; Yang, L.; Huang, J.; Peng, R.; Wang, X.; He, W.; Bai, L.; Zhou, Y.; Zhang, B.; et al. First-line cetuximab improves the efficacy of subsequent bevacizumab for RAS wild-type left-sided metastatic colorectal cancer: An observational retrospective study. Sci. Rep. 2020, 10, 12336. [CrossRef] [PubMed]

110. Kamba, T.; McDonald, D.M. Mechanisms of adverse effects of anti-VEGF therapy for cancer. Br. J. Cancer 2007, 96, 1788-1795. [CrossRef] [PubMed]

111. Riva, P.; Marangolo, M.; Tison, V.; Armaroli, L.; Moscatelli, G.; Franceschi, G.; Spinelli, A.; Vecchietti, G.; Morigi, P.; Tassini, R.; et al. Treatment of metastatic colorectal cancer by means of specific monoclonal antibodies conjugated with iodine-131: A phase II study. Int. J. Rad. Appl. Instrum. B 1991, 18, 109-119. [CrossRef]

112. Tsai, M.-H.; Pan, C.-H.; Peng, C.-L.; Shieh, M.-J. Panitumumab-Conjugated Pt-Drug Nanomedicine for Enhanced Efficacy of Combination Targeted Chemotherapy against Colorectal Cancer. Adv. Healthc. Mater. 2017, 6, 1700111. [CrossRef]

113. Keam, S.J. Trastuzumab Deruxtecan: First Approval. Drugs 2020, 80, 501-508. [CrossRef]

114. DS-8201a in Human Epidermal Growth Factor Receptor2 (HER2)-Expressing Colorectal Cancer (DESTINY-CRC01). Available online: https: / / ClinicalTrials.gov/show / NCT03384940 (accessed on 11 October 2021).

115. Bacac, M.; Fauti, T.; Sam, J.; Colombetti, S.; Weinzierl, T.; Ouaret, D.; Bodmer, W.; Lehmann, S.; Hofer, T.; Hosse, R.J.; et al. A Novel Carcinoembryonic Antigen T-Cell Bispecific Antibody (CEA TCB) for the Treatment of Solid Tumors. Clin Cancer Res. 2016, 22, 3286-3297. [CrossRef]

116. Zhao, L.; Yang, Y.; Zhou, P.; Ma, H.; Zhao, X.; He, X.; Wang, T.; Zhang, J.; Liu, Y.; Zhang, T. Targeting CD133high Colorectal Cancer Cells In Vitro and In Vivo With an Asymmetric Bispecific Antibody. J. Immunother. 2015, 38, 217-228. [CrossRef]

117. Douglass, J.; Hsiue, E.H.-C.; Mog, B.J.; Hwang, M.S.; Di Napoli, S.R.; Pearlman, A.H.; Miller, M.S.; Wright, K.M.; Azurmendi, P.A.; Wang, Q.; et al. Bispecific antibodies targeting mutant RAS neoantigens. Sci. Immunol. 2021, 6, eabd5515. [CrossRef]

118. Hsiue, E.H.-C.; Wright, K.M.; Douglass, J.; Hwang, M.S.; Mog, B.J.; Pearlman, A.H.; Paul, S.; Di Napoli, S.R.; Konig, M.F.; Wang, Q.; et al. Targeting a neoantigen derived from a common TP53 mutation. Science 2021, 371, eabc8697. [CrossRef]

119. Skora, A.D.; Douglass, J.; Hwang, M.S.; Tam, A.J.; Blosser, R.L.; Gabelli, S.B.; Cao, J.; Diaz, L.A.; Papadopoulos, N.; Kinzler, K.W.; et al. Generation of MANAbodies specific to HLA-restricted epitopes encoded by somatically mutated genes. Proc. Natl. Acad. Sci. USA 2015, 112, 9967-9972. [CrossRef] [PubMed]

120. de Bruin, R.C.G.; Veluchamy, J.P.; Lougheed, S.M.; Schneiders, F.L.; Lopez-Lastra, S.; Lameris, R.; Stam, A.G.; Sebestyen, Z.; Kuball, J.; Molthoff, C.F.M.; et al. A bispecific nanobody approach to leverage the potent and widely applicable tumor cytolytic capacity of V $\gamma 9 \mathrm{~V} \delta 2-\mathrm{T}$ cells. Oncoimmunolog 2017, 7, e1375641. [CrossRef] [PubMed]

121. Mueller, T.; Freystein, J.; Lucas, H.; Schmoll, H.-J. Efficacy of a Bispecific Antibody Co-Targeting VEGFA and Ang-2 in Combination with Chemotherapy in a Chemoresistant Colorectal Carcinoma Xenograft Model. Molecules 2019, 24, 2865. [CrossRef] [PubMed]

122. Xu, M.; Wen, Y.; Liu, Y.; Tan, X.; Chen, X.; Zhu, X.; Wei, C.; Chen, L.; Wang, Z.; Liu, J.; et al. Hollow mesoporous ruthenium nanoparticles conjugated bispecific antibody for targeted anti-colorectal cancer response of combination therapy. Nanoscale 2019, 11, 9661-9678. [CrossRef]

123. A Study of $\mathrm{XmAb} 22841$ Monotherapy \& in Combination w/ Pembrolizumab in Subjects w/ Selected Advanced Solid Tumors. Available online: https:/ / clinicaltrials.gov/ct2/show /NCT03849469 (accessed on 11 October 2021).

124. Chames, P.; Van Regenmortel, M.; Weiss, E.; Baty, D. Therapeutic antibodies: Successes, limitations and hopes for the future. Br. J. Pharmacol. 2009, 157, 220-233. [CrossRef] 
125. Moradi, A.; Pourseif, M.M.; Jafari, B.; Parvizpour, S.; Omidi, Y. Nanobody-based therapeutics against colorectal cancer: Precision therapies based on the personal mutanome profile and tumor neoantigens. Pharmacol. Res. 2020, 156, 104790. [CrossRef]

126. First in Human Trial of TAS266 in Patients With Advanced Solid Tumors. Available online: https://ClinicalTrials.gov/show/ NCT01529307 (accessed on 11 October 2021).

127. $\alpha$ PD1-MSLN-CAR T Cells for the Treatment of MSLN-positive Advanced Solid Tumors. Available online: https://clinicaltrials. gov/ct2/show / NCT04503980 (accessed on 11 October 2021).

128. Wrobel, P.; Ahmed, S. Current status of immunotherapy in metastatic colorectal cancer. Int. J. Colorectal. Dis. 2019, 34, 13-25. [CrossRef]

129. Geevarghese, S.K.; Geller, D.A.; De Haan, H.A.; Hörer, M.; Knoll, A.E.; Mescheder, A.; Nemunaitis, J.; Reid, T.R.; Sze, D.Y.; Tanabe, K.K.; et al. Phase I/II study of oncolytic herpes simplex virus NV1020 in patients with extensively pretreated refractory colorectal cancer metastatic to the liver. Hum. Gene Ther. 2010, 21, 1119-1128. [CrossRef]

130. Pexastimogene Devacirepvec: National Cancer Institute. Available online: https://www.cancer.gov/publications/dictionaries/ cancer-drug/def/pexastimogene-devacirepvec (accessed on 11 October 2021).

131. A Trial of JX-594 in Refractory Colorectal Carcinoma. Available online: https://clinicaltrials.gov/ct2/show/NCT01469611 (accessed on 11 October 2021).

132. Park, S.H.; Breitbach, C.J.; Lee, J.; Park, J.O.; Lim, H.Y.; Kang, W.K.; Moon, A.; Mun, J.-H.; Sommermann, E.M.; Avidal, L.M.; et al Phase 1b Trial of Biweekly Intravenous Pexa-Vec (JX-594), an Oncolytic and Immunotherapeutic Vaccinia Virus in Colorectal Cancer. Mol. Ther. 2015, 23, 1532-1540. [CrossRef]

133. Monge, B.M.; Xie, C.; Steinberg, S.M.; Fioraventi, S.; Walker, M.; Mabry-Hrones, D.; Wood, B.J.; Kleiner, E.D.; Greten, T.F. A phase I/II study of Pexa-Vec oncolytic virus in combination with immune checkpoint inhibition in refractory colorectal cancer. J. Clin. Oncol. 2020, 38 (Suppl. 4), 117.

134. Song, H.; Zhong, L.-P.; He, J.; Huang, Y.; Zhao, Y.-X. Application of Newcastle disease virus in the treatment of colorectal cancer. World J. Clin. Cases 2019, 7, 2143-2154. [CrossRef] [PubMed]

135. Puccini, A.; Battaglin, F.; Iaia, M.L.; Lenz, H.-J.; Salem, E.M. Overcoming resistance to anti-PD1 and anti-PD-L1 treatment in gastrointestinal malignancies. J. Immunother. Cancer 2020, 8, e000404. [CrossRef] [PubMed]

136. Fifis, T.; Lam, I.; Lin, D.; Malcontenti-Wilson, C.; Christophi, C.; Loveland, B. Vaccination with in vitro grown whole tumor cells induces strong immune responses and retards tumor growth in a murine model of colorectal liver metastases. Vaccine 2008, 26, 241-249. [CrossRef] [PubMed]

137. Schmidt, W.; Steinlein, P.; Buschle, M.; Schweighoffer, T.; Herbst, E.; Mechtler, K.; Kirlappos, H.; Birnstie, M.L. Transloading of tumor cells with foreign major histocompatibility complex class I peptide ligand: A novel general strategy for the generation of potent cancer vaccines. Proc. Natl. Acad. Sci. USA 1996, 93, 9759-9763. [CrossRef]

138. de Weger, V.A.; Turksma, A.W.; Voorham, Q.J.M.; Euler, Z.; Bril, H.; van den Eertwegh, A.J.; Bloemena, E.; Pinedo, H.M.; Vermorken, J.B.; van Tinteren, H.; et al. Clinical effects of adjuvant active specific immunotherapy differ between patients with microsatellite-stable and microsatellite-instable colon cancer. Clin. Cancer Res. 2012, 18, 882-889. [CrossRef]

139. Harris, J.E.; Ryan, L.; Hoover, H.C., Jr.; Stuart, R.K.; Oken, M.M.; Benson, A.B.; Mansour, E.; Haller, D.G.; Manola, J.; Hanna, M.G., Jr. Adjuvant active specific immunotherapy for stage II and III colon cancer with an autologous tumor cell vaccine: Eastern Cooperative Oncology Group Study E5283. J. Clin. Oncol. 2000, 18, 148-157. [CrossRef]

140. Tagliamonte, M.; Petrizzo, A.; Tornesello, M.L.; Buonaguro, F.M.; Buonaguro, L. Antigen-specific vaccines for cancer treatment. Hum. Vaccin. Immunother. 2014, 10, 3332-3346. [CrossRef]

141. George, D.J.; Nabhan, C.; Devries, T.; Whitmore, J.B.; Gomella, L.G. Survival Outcomes of Sipuleucel-T Phase III Studies: Impact of Control-Arm Cross-Over to Salvage Immunotherapy. Cancer Immunol. Res. 2015, 3, 1063-1069. [CrossRef]

142. Mirlekar, B.; Pylayeva-Gupta, Y. IL-12 Family Cytokines in Cancer and Immunotherapy. Cancers 2021, 13, 167. [CrossRef]

143. Cytokines and Their Side Effects: American Cancer Society. Available online: https://www.cancer.org/treatment/treatmentsand-side-effects/treatment-types/immunotherapy / cytokines.html (accessed on 11 October 2021).

144. Chulpanova, D.S.; Kitaeva, K.V.; Green, A.R.; Rizvanov, A.A.; Solovyeva, V.V. Molecular Aspects and Future Perspectives of Cytokine-Based Anti-cancer Immunotherapy. Front. Cell Dev. Biol. 2020, 8, 402. [CrossRef]

145. Akdis, M.; Aab, A.; Altunbulakli, C.; Azkur, K.; Costa, R.; Crameri, R.; Duan, S.; Eiwegger, T.; Eljaszewicz, A.; Ferst, I.R.; et al Interleukins (from IL-1 to IL-38), interferons, transforming growth factor $\beta$, and TNF- $\alpha$ : Receptors, functions, and roles in diseases. J. Allergy Clin. Immunol. 2016, 138, 984-1010. [CrossRef] [PubMed]

146. Parker, B.S.; Rautela, J.; Hertzog, P.J. Antitumour actions of interferons: Implications for cancer therapy. Nat. Rev. Cancer 2016, 16, 131-144. [CrossRef] [PubMed]

147. Jorgovanovic, D.; Song, M.; Wang, L.; Zhang, Y. Roles of IFN- $\gamma$ in tumor progression and regression: A review. Biomark. Res. 2020, 8, 49. [CrossRef] [PubMed]

148. Slattery, M.L.; Lundgreen, A.; Bondurant, K.L.; Wolff, R.K. Interferon-signaling pathway: Associations with colon and rectal cancer risk and subsequent survival. Carcinogenesis 2011, 32, 1660-1667. [CrossRef]

149. Zaidi, M.R.; Merlino, G. The two faces of interferon- $\gamma$ in cancer. Clin. Cancer Res. 2011, 17, 6118-6124. [CrossRef]

150. Zaidi, M.R. The Interferon-Gamma Paradox in Cancer. J. Interferon. Cytokine Res. 2019, 39, 30-38. [CrossRef] 
151. Hanada, T.; Kobayashi, T.; Chinen, T.; Saeki, K.; Takaki, H.; Koga, K.; Minoda, Y.; Sanada, T.; Yoshioka, T.; Mimata, H.; et al. IFNgamma-dependent, spontaneous development of colorectal carcinomas in SOCS1-deficient mice. J. Exp. Med. 2006, 203, 1391-1397. [CrossRef]

152. Wiesenfeld, M.; O'Connell, M.J.; Wieand, H.S.; Gonchoroff, N.J.; Donohue, J.H.; Jr, R.J.F.; Krook, E.J.; Mailliard, A.J.; Gerstner, J.B.; Pazdur, R. Controlled clinical trial of interferon-gamma as postoperative surgical adjuvant therapy for colon cancer. J. Clin. Oncol. 1995, 13, 2324-2329. [CrossRef]

153. Study of Gamma Interfereon in Metastatic Colorectal Carcinoma. Available online: https://ClinicalTrials.gov/show/NCT00786 643 (accessed on 11 October 2021).

154. Qiu, Y.; Su, M.; Liu, L.; Tang, Y.; Pan, Y.; Sun, J. Clinical Application of Cytokines in Cancer Immunotherapy. Drug Des. Dev. Ther. 2021, 15, 2269-2287. [CrossRef]

155. Chon, H.J.; Kim, H.; Noh, J.H.; Yang, H.; Lee, W.S.; Kong, S.J.; Lee, S.J.; Lee, Y.S.; Kim, W.R.; Kim, J.H.; et al. STING signaling is a potential immunotherapeutic target in colorectal cancer. J. Cancer 2019, 10, 4932-4938. [CrossRef]

156. Chen, S.Y.; Chen, S.; Feng, W.; Li, Z.; Luo, X.; Zhu, X. A STING-related prognostic score predicts high-risk patients of colorectal cancer and provides insights into immunotherapy. Ann. Transl. Med. 2021, 9, 14. [CrossRef] [PubMed]

157. Kim, D.; Endo, A.; Fang, F.G.; Huang, K.; Bao, X.; Choi, H.; Majumder, U.; Shen, Y.Y.; Mathieu, S.; Zhu, X.; et al. E7766, a Macrocycle-Bridged Stimulator of Interferon Genes (STING) Agonist with Potent Pan-Genotypic Activity. ChemMedChem 2021, 16, 1740-1743. [CrossRef] [PubMed]

158. Stewart, A.K. Medicine. How thalidomide works against cancer. Science 2014, 343, 256-257. [CrossRef] [PubMed]

159. Liu, W.M.; Henry, J.Y.; Meyer, B.; Bartlett, J.B.; Dalgleish, A.G.; Galustian, C. Inhibition of metastatic potential in colorectal carcinoma in vivo and in vitro using immunomodulatory drugs (IMiDs). Br. J. Cancer 2009, 101, 803-812. [CrossRef]

160. Goldstein, M.J.; Leighton, J.C.; Chapman, A.; Muskett, A.; Sharan, K.; Sansom, J.; Mitchell, E.P. Phase I trial of thalidomide and capecitabine for treatment of metastatic colorectal cancer. J. Clin. Oncol. 2006, 24 (Suppl. 18), 13552. [CrossRef]

161. Kroschinsky, F.; Stölzel, F.; von Bonin, S.; Beutel, G.; Kochanek, M.; Kiehl, M.; Schellongowski, P. New drugs, new toxicities: Severe side effects of modern targeted and immunotherapy of cancer and their management. Crit. Care 2017, 21, 89. [CrossRef]

162. Armaghany, T.; Wilson, J.D.; Chu, Q.; Mills, G. Genetic alterations in colorectal cancer. Gastrointest. Cancer Res. GCR 2012, 5, $19-27$.

163. Wu, C.-E.; Yeh, D.-W.; Pan, Y.-R.; Huang, W.-K.; Chen, M.-H.; Chang, J.; Chen, J.-S.; Wang, Y.-C.; Yeh, C.-N. Chromosomal Instability May Not Be a Predictor for Immune Checkpoint Inhibitors from a Comprehensive Bioinformatics Analysis. Life 2020, 10, 276. [CrossRef]

164. Walther, A.; Houlston, R.; Tomlinson, I. Association between chromosomal instability and prognosis in colorectal cancer: A meta-analysis. Gut 2008, 57, 941-950. [CrossRef]

165. Hamarsheh, S.; Groß, O.; Brummer, T.; Zeiser, R. Immune modulatory effects of oncogenic KRAS in cancer. Nat. Commun. 2020, 11, 5439. [CrossRef]

166. Liu, J.; Huang, X.; Liu, H.; Wei, C.; Ru, H.; Qin, H.; Lai, H.; Meng, Y.; Wu, G.; Xie, W.; et al. Immune landscape and prognostic immune-related genes in KRAS-mutant colorectal cancer patients. J. Transl. Med. 2021, 19, 27. [CrossRef]

167. Chen, N.; Fang, W.; Lin, Z.; Peng, P.; Wang, J.; Zhan, J.; Hong, S.; Huang, J.; Liu, L.; Sheng, J.; et al. KRAS mutation-induced upregulation of PD-L1 mediates immune escape in human lung adenocarcinoma. Cancer Immunology. Immunotherapy 2017, 66, $1175-1187$.

168. Zhang, L.; Shay, J.W. Multiple Roles of APC and its Therapeutic Implications in Colorectal Cancer. JNCI J. Natl. Cancer Inst. 2017, 109, djw332. [CrossRef] [PubMed]

169. Grasso, C.S.; Giannakis, M.; Wells, D.K.; Hamada, T.; Mu, X.J.; Quist, M.; Nowak, J.A.; Nishihara, R.; Qian, Z.R.; Inamura, K.; et al. Genetic Mechanisms of Immune Evasion in Colorectal Cancer. Cancer Discov. 2018, 8, 730-749. [CrossRef] [PubMed]

170. Zhu, K.; Wang, J.; Zhu, J.; Jiang, J.; Shou, J.; Chen, X. p53 induces TAP1 and enhances the transport of MHC class I peptides. Oncogene 1999, 18, 7740-7747. [CrossRef]

171. Zhao, P.; Li, L.; Jiang, X.; Li, Q. Mismatch repair deficiency/microsatellite instability-high as a predictor for anti-PD-1/PD-L1 immunotherapy efficacy. J. Hematol. Oncol. 2019, 12, 54. [CrossRef]

172. Hamada, T.; Soong, T.R.; Masugi, Y.; Kosumi, K.; Nowak, J.A.; Da Silva, A.; Mu, X.J.; Twombly, T.S.; Koh, H.; Yang, J.; et al. TIME (Tumor Immunity in the MicroEnvironment) classification based on tumor CD274 (PD-L1) expression status and tumor-infiltrating lymphocytes in colorectal carcinomas. Oncoimmunology 2018, 7, e1442999. [CrossRef]

173. Kim, J.H.; Park, H.E.; Cho, N.-Y.; Lee, H.S.; Kang, G.H. Characterisation of PD-L1-positive subsets of microsatellite-unstable colorectal cancers. Br. J. Cancer 2016, 115, 490-496. [CrossRef]

174. Marcus, L.; Fashoyin-Aje, L.A.; Donoghue, M.; Yuan, M.; Rodriguez, L.; Gallagher, P.S.; Philip, R.; Ghosh, S.; Theoret, M.R.; Beaver, J.A.; et al. FDA Approval Summary: Pembrolizumab for the Treatment of Tumor Mutational Burden-High Solid Tumors. Clin. Cancer Res. 2021, 27, 4685-4689. [CrossRef]

175. Samuels, Y.; Wang, Z.; Bardelli, A.; Silliman, N.; Ptak, J.; Szabo, S.; Yan, H.; Gazdar, A.; Powell, S.M.; Riggins, G.J.; et al. High Frequency of Mutations of the PIK3CA Gene in Human Cancers. Science 2004, 304, 554. [CrossRef]

176. Nusrat, M.; Roszik, J.; Katkhuda, R.; Menter, D.; Raghav, K.P.S.; Morris, V.K.; Sharma, P.; Allison, J.P.; Blando, J.M.; Maru, D.M.; et al. Association of PIK3CA mutations (mut) with immune engagement and clinical benefit from immunotherapy in microsatellite stable (MSS) colorectal cancer (CRC) patients (pts). J. Clin. Oncol. 2019, 37 (Suppl. 15), 3604. [CrossRef] 
177. Nassif, N.T.; Lobo, G.P.; Wu, X.; Henderson, A.C.J.; Morrison, C.D.; Eng, C.; Jalaludin, B.; Segelov, E. PTEN mutations are common in sporadic microsatellite stable colorectal cancer. Oncogene 2004, 23, 617-628. [CrossRef] [PubMed]

178. Vidotto, T.; Melo, C.; Castelli, E.; Koti, M.; dos Reis, R.B.; Squire, J.A. Emerging role of PTEN loss in evasion of the immune response to tumours. Br. J. Cancer 2020, 122, 1732-1743. [CrossRef] [PubMed]

179. Lin, Z.; Huang, L.; Li, S.L.; Gu, J.; Cui, X.; Zhou, Y. PTEN loss correlates with T cell exclusion across human cancers. BMC Cancer 2021, 21, 429. [CrossRef]

180. Kim, B.-G.; Malek, E.; Choi, S.H.; Ignatz-Hoover, J.J.; Driscoll, J.J. Novel therapies emerging in oncology to target the TGF- $\beta$ pathway. J. Hematol. Oncol. 2021, 14, 55. [CrossRef]

181. Bai, X.; Yi, M.; Jiao, Y.; Chu, Q.; Wu, K. Blocking TGF- $\beta$ Signaling To Enhance The Efficacy Of Immune Checkpoint Inhibitor. Onco. Targets Ther. 2019, 12, 9527-9538. [CrossRef]

182. Grady, W.M.; Myeroff, L.L.; Swinler, S.E.; Rajput, A.; Thiagalingman, S.; Lutterbaugh, J.D.; Neumann, A.; Brattain, M.G.; Chang, J.; Kim, S.-J.; et al. Mutational Inactivation of Transforming Growth Factor $\beta$ Receptor Type II in Microsatellite Stable Colon Cancers. Cancer Res. 1999, 59, 320-324.

183. Li, T.; Wang, H.; Xu, J.; Li, C.; Zhang, Y.; Wang, G.; Liu, Y.; Cai, S.; Fang, W.; Li, J.; et al. TGFBR2 mutation predicts resistance to immune checkpoint inhibitors in patients with non-small cell lung cancer. Ther. Adv. Med. Oncol. 2021, 13, 1-14. [CrossRef]

184. Hu, Y.; Chen, W.; Yan, Z.; Ma, J.; Zhu, F.; Hue, J. Prognostic value of PD-L1 expression in patients with pancreatic cancer: A PRISMA-compliant meta-analysis. Medicine 2019, 98, e14006. [CrossRef]

185. Droeser, R.A.; Hirt, C.; Viehl, C.T.; Frey, D.M.; Nebiker, C.; Huber, X.; Zlobec, I.; Eppenberger-Castori, S.; Tzankov, A.; Rosso, R.; et al. Clinical impact of programmed cell death ligand 1 expression in colorectal cancer. Eur. J. Cancer 2013, 49, $2233-2242$. [CrossRef]

186. Klein, S.; Mauch, C.; Brinker, K.; Noh, K.-W.; Knez, S.; Büttner, R.; Quaas, A.; Helbig, D. Tumor infiltrating lymphocyte clusters are associated with response to immune checkpoint inhibition in BRAF V600E/K mutated malignant melanomas. Sci. Rep. 2021, 11, 1834. [CrossRef] [PubMed]

187. Li, M.; Li, W.; Yang, X.; Wang, H.; Peng, Y.; Yin, J.; Lu, Y.; Liu, L.; Shang, J.; Zhao, Q. An immune landscape based prognostic signature predicts the immune status and immunotherapeutic responses of patients with colorectal cancer. Life Sci. 2020, 261, 118368. [CrossRef] [PubMed]

188. Correale, P.; Rotundo, M.S.; Del Vecchio, M.T.; Remondo, C.; Migali, C.; Ginanneschi, C.; Tsang, K.Y.; Licchetta, A.; Mannucci, S.; Loiacono, L.; et al. Regulatory (FoxP3+) T-cell tumor infiltration is a favorable prognostic factor in advanced colon cancer patients undergoing chemo or chemoimmunotherapy. J. Immunother. 2010, 33, 435-441. [CrossRef]

189. Tang, Y.-Q.; Chen, T.-F.; Zhang, Y.; Zhao, X.-C.; Zhang, Y.-Z.; Wang, G.-Q.; Huang, M.-L.; Cai, S.-L.; Zhao, J.; Wei, B.; et al. The tumor immune microenvironment transcriptomic subtypes of colorectal cancer for prognosis and development of precise immunotherapy. Gastroenterol. Rep. 2020, 8, 381-389. [CrossRef] [PubMed]

190. Tamura, K.; Hazama, S.; Yamaguchi, R.; Imoto, S.; Takenouchi, H.; Inoue, Y.; Kanekiyo, S.; Shindo, Y.; Miyano, S.; Nakamura, Y.; et al. Characterization of the $\mathrm{T}$ cell repertoire by deep $\mathrm{T}$ cell receptor sequencing in tissues and blood from patients with advanced colorectal cancer. Oncol. Lett. 2016, 11, 3643-3649. [CrossRef]

191. Liu, X.; Cui, Y.; Zhang, Y.; Liu, Z.; Zhang, Q.; Wu, W.; Zheng, Z.; Li, S.; Zhang, Z.; Li, Y. A comprehensive study of immunology repertoires in both preoperative stage and postoperative stage in patients with colorectal cancer. Mol. Genet. Genom. Med. 2019, 7, e504. [CrossRef]

192. Lin, Y.; Xu, J.; Lan, H. Tumor-associated macrophages in tumor metastasis: Biological roles and clinical therapeutic applications. J. Hematol. Oncol. 2019, 12, 76. [CrossRef]

193. Zhang, S.-Y.; Song, X.-Y.; Li, Y.; Ye, L.-L.; Zhou, Q.; Yang, W.-B. Tumor-associated macrophages: A promising target for a cancer immunotherapeutic strategy. Pharmacol. Res. 2020, 161, 105111. [CrossRef]

194. Pinto, M.L.; Rios, E.; Durães, C.; Ribeiro, R.; Machado, J.C.; Mantovani, A.; Barbosa, M.A.; Carneiro, F.; Oliveira, M.J. The Two Faces of Tumor-Associated Macrophages and Their Clinical Significance in Colorectal Cancer. Front. Immunol. 2019, $10,1875$. [CrossRef]

195. Larionova, I.; Tuguzbaeva, G.; Ponomaryova, A.; Stakheyeva, M.; Cherdyntseva, N.; Pavlov, V.; Choinzonov, E.; Kzhyshkowska, J. Tumor-Associated Macrophages in Human Breast, Colorectal, Lung, Ovarian and Prostate Cancers. Front. Oncol. 2020, 10, 566511. [CrossRef]

196. Ganesh, K.; Stadler, Z.K.; Cercek, A.; Mendelsohn, R.B.; Shia, J.; Segal, N.H.; Diaz, L.A., Jr. Immunotherapy in colorectal cancer: Rationale, challenges and potential. Nat. Rev. Gastroenterol. Hepatol. 2019, 16, 361-375. [CrossRef] [PubMed]

197. Mager, L.F.; Burkhard, R.; Pett, N.; Cooke, N.C.A.; Brown, K.; Ramay, H.; Paik, S.; Stagg, J.; Groves, R.A.; Gallo, M.; et al. Microbiome-derived inosine modulates response to checkpoint inhibitor immunotherapy. Science 2020, 369, 1481-1489. [CrossRef] [PubMed]

198. Peng, Z.; Cheng, S.; Kou, Y.; Wang, Z.; Jin, R.; Hu, H.; Zhang, X.; Gong, F.-F.; Li, J.; Lu, M.; et al. The Gut Microbiome Is Associated with Clinical Response to Anti-PD-1/PD-L1 Immunotherapy in Gastrointestinal Cancer. Cancer Immunol. Res. 2020, 8, $1251-1261$. [CrossRef] [PubMed]

199. Choi, J.; Maeng, H.G.; Lee, S.J.; Kim, Y.J.; Kim, D.W.; Na Lee, H.; Namgung, J.H.; Oh, H.-M.; Kim, T.J.; Jeong, J.E.; et al. Diagnostic value of peripheral blood immune profiling in colorectal cancer. Ann. Surg. Treat Res. 2018, 94, 312-321. [CrossRef] 
200. Tang, Y.-P.; Xie, M.-Z.; Li, K.-Z.; Li, J.-L.; Cai, Z.-M.; Hu, B.-L. Prognostic value of peripheral blood natural killer cells in colorectal cancer. BMC Gastroenterol. 2020, 20, 31. [CrossRef]

201. Saied, A.; Licata, A.L.; Burga, R.A.; Thorn, M.; McCormack, A.E.; Stainken, B.F.; Assanah, E.O.; Khare, P.D.; Davies, R.G.; Espat, N.J.; et al. Neutrophil: Lymphocyte ratios and serum cytokine changes after hepatic artery chimeric antigen receptor-modified T-cell infusions for liver metastases. Cancer Gene Ther. 2014, 21, 457-462. [CrossRef]

202. Reece, M.; Saluja, H.; Hollington, P.; Karapetis, C.; Vatandoust, S.; Young, G.; Symonds, E.L. The Use of Circulating Tumor DNA to Monitor and Predict Response to Treatment in Colorectal Cancer. Front. Genet. 2019, 10, 1118. [CrossRef]

203. Calu, V.; Ionescu, A.; Stanca, L.; Geicu, O.I.; Iordache, F.; Pisoschi, A.M.; Serban, A.I.; Bilteanu, L. Key biomarkers within the colorectal cancer related inflammatory microenvironment. Sci. Rep. 2021, 11, 7940. [CrossRef]

204. Wang, M.; Zhai, X.; Li, J.; Guan, J.; Xu, S.; Li, Y.; Zhu, H. The Role of Cytokines in Predicting the Response and Adverse Events Related to Immune Checkpoint Inhibitors. Front. Immunol. 2021, 12, 2894. [CrossRef]

205. Liu, C.; Liu, R.; Wang, B.; Lian, J.; Yao, Y.; Sun, H.; Zhang, C.; Fang, L.; Guan, X.; Shi, J.; et al. Blocking IL-17A enhances tumor response to anti-PD-1 immunotherapy in microsatellite stable colorectal cancer. J. Immunother. Cancer 2021, 9, e001895. [CrossRef]

206. Chang, Y.-C.; Chan, M.-H.; Li, C.-H.; Fang, C.-Y.; Hsiao, M.; Chen, C.-L. Exosomal Components and Modulators in Colorectal Cancer: Novel Diagnosis and Prognosis Biomarkers. Biomedicines 2021, 9, 931. [CrossRef] [PubMed]

207. Clerici, S.P.; Peppelenbosch, M.; Fuhler, G.; Consonni, S.R.; Ferreira-Halder, C.V. Colorectal Cancer Cell-Derived Small Extracellular Vesicles Educate Human Fibroblasts to Stimulate Migratory Capacity. Front. Cell Dev. Biol. 2021, 9, 696373. [CrossRef] [PubMed]

208. Zhou, E.; Li, Y.; Wu, F.; Guo, M.; Xu, J.; Wang, S.; Tan, Q.; Ma, P.; Song, S.; Jin, Y. Circulating extracellular vesicles are effective biomarkers for predicting response to cancer therapy. EBioMedicine 2021, 67, 103365. [CrossRef] [PubMed]

209. Foy, J.P.; Bertolus, C.; Michallet, M.-C.; Deneuve, S.; Incitti, R.; Bendriss-Vermare, N.; Albaret, M.-A.; Ortiz-Curan, S.; Thomas, E.; Colombe, A.; et al. The immune microenvironment of HPV-negative oral squamous cell carcinoma from never-smokers and never-drinkers patients suggests higher clinical benefit of IDO1 and PD1/PD-L1 blockade. Ann. Oncol. 2017, 28, 1934-1941. [CrossRef]

210. Lin, Y.-M.; Sung, W.-W.; Hsieh, M.-J.; Tsai, S.-C.; Lai, H.-W.; Yang, S.-M.; Shen, K.-H.; Chen, M.-K.; Lee, H.; Yeh, K.-T.; et al. High PD-L1 Expression Correlates with Metastasis and Poor Prognosis in Oral Squamous Cell Carcinoma. PLoS ONE 2015, 10, e0142656. [CrossRef]

211. Szabo, G.; Catalano, N.; White, B.; Mandrekar, P. Acute alcohol consumption inhibits accessory cell function of monocytes and dendritic cells. Alcohol Clin. Exp. Res. 2004, 28, 824-828. [CrossRef]

212. Wang, Z.; Aguilar, E.G.; Luna, J.I.; Dunai, C.; Khuat, L.T.; Le, C.; Mirsoian, A.; Minnar, C.M.; Stoffel, K.M.; Sturgill, I.R.; et al. Paradoxical effects of obesity on T cell function during tumor progression and PD-1 checkpoint blockade. Nat. Med. 2019, 25, 141-151. [CrossRef]

213. Wang, Y.; Dong, T.; Xuan, Q.; Zhao, H.; Qin, L.; Zhang, Q. Lymphocyte-Activation Gene-3 Expression and Prognostic Value in Neoadjuvant-Treated Triple-Negative Breast Cancer. J. Breast Cancer 2018, 21, 124-133. [CrossRef]

214. Heidelberger, V.; Goldwasser, F.; Kramkimel, N.; Jouinot, A.; Huillard, O.; Boudou-Rouquette, P.; Chanal, J.; Arrondeau, J.; Franck, N.; Alexandre, J.; et al. Sarcopenic overweight is associated with early acute limiting toxicity of anti-PD1 checkpoint inhibitors in melanoma patients. Investig. New Drugs 2017, 35, 436-441. [CrossRef]

215. Naik, G.S.; Waikar, S.S.; Johnson, A.E.W.; Buchbinder, E.I.; Haq, R.; Hodi, F.S.; Schoenfeld, J.D.; Ott, P.A. Complex inter-relationship of body mass index, gender and serum creatinine on survival: Exploring the obesity paradox in melanoma patients treated with checkpoint inhibition. J. Immunother. Cancer 2019, 7, 89. [CrossRef]

216. McQuade, J.L.; Daniel, C.R.; Hess, K.R.; Mak, C.; Wang, D.Y.; Rai, R.R.; Park, J.J.; Haydu, L.E.; Spencer, C.; Wongchenko, M.; et al. Association of body-mass index and outcomes in patients with metastatic melanoma treated with targeted therapy, immunotherapy, or chemotherapy: A retrospective, multicohort analysis. Lancet Oncol. 2018, 19, 310-322. [CrossRef]

217. Abdel-Rahman, O. Smoking and EGFR status may predict outcomes of advanced NSCLC treated with PD-(L)1 inhibitors beyond first line: A meta-analysis. Clin. Respir. J. 2018, 12, 1809-1819. [CrossRef] [PubMed]

218. Lin, S.-Y.; Yang, C.-Y.; Liao, B.-C.; Ho, C.-C.; Liao, W.-Y.; Chen, K.-Y.; Tsai, T.-H.; Hsu, C.-L.; Hsu, W.-H.; Su, K.-Y.; et al. Tumor PD-L1 Expression and Clinical Outcomes in Advanced-stage Non-Small Cell Lung Cancer Patients Treated with Nivolumab or Pembrolizumab: Real-World Data in Taiwan. J. Cancer 2018, 9, 1813-1820. [CrossRef] [PubMed]

219. Nishino, M.; Dahlberg, S.E.; Adeni, A.E.; Lydon, C.A.; Hatabu, H.; Janne, P.A.; Hodi, F.S.; Awad, M.M. Tumor Response Dynamics of Advanced Non-small Cell Lung Cancer Patients Treated with PD-1 Inhibitors: Imaging Markers for Treatment Outcome. Clin. Cancer Res. 2017, 23, 5737-5744. [CrossRef] [PubMed]

220. Reis, H.; Metzenmacher, M.; Goetz, M.; Savvidou, N.; Darwiche, K.; Aigner, C.; Herold, T.; Eberhardt, W.E.; Skiba, C.; Hense, J.; et al. MET Expression in Advanced Non-Small-Cell Lung Cancer: Effect on Clinical Outcomes of Chemotherapy, Targeted Therapy, and Immunotherapy. Clin. Lung Cancer 2018, 19, e441-e463. [CrossRef]

221. Rizvi, N.A.; Hellmann, M.D.; Snyder, A.; Kvistborg, P.; Makarov, V.; Havel, J.J.; Lee, W.; Yuan, J.; Wong, P.; Ho, T.S.; et al. Cancer immunology. Mutational landscape determines sensitivity to PD-1 blockade in non-small cell lung cancer. Science 2015, 348, 124-128. [CrossRef]

222. Schreiber, R.D.; Old, L.J.; Smyth, M.J. Cancer immunoediting: Integrating immunity's roles in cancer suppression and promotion. Science 2011, 331, 1565-1570. [CrossRef] 
223. Polanczyk, M.J.; Hopke, C.; Vandenbark, A.A.; Offner, H. Treg suppressive activity involves estrogen-dependent expression of programmed death-1 (PD-1). Int. Immunol. 2007, 19, 337-343. [CrossRef]

224. Deshpande, R.P.; Sharma, S.; Watabe, K. The Confounders of Cancer Immunotherapy: Roles of Lifestyle, Metabolic Disorders and Sociological Factors. Cancers 2020, 12, 2983. [CrossRef]

225. Fujiyoshi, K.; Chen, Y.; Haruki, K.; Ugai, T.; Kishikawa, J.; Hamada, T.; Liu, L.; Arima, K.; Borowsky, J.; Väyrynen, J.P.; et al. Smoking Status at Diagnosis and Colorectal Cancer Prognosis According to Tumor Lymphocytic Reaction. JNCI Cancer Spectr. 2020, 4, pkaa040. [CrossRef]

226. Crockett, S.D.; Long, M.D.; Dellon, E.S.; Martin, C.F.; Galanko, J.A.; Sandler, R.S. Inverse relationship between moderate alcohol intake and rectal cancer: Analysis of the North Carolina Colon Cancer Study. Dis. Colon Rectum 2011, 54, 887-894. [CrossRef] [PubMed]

227. Lin, A.; Zhang, J.; Luo, P. Crosstalk Between the MSI Status and Tumor Microenvironment in Colorectal Cancer. Front. Immunol. 2020, 11, 2039. [CrossRef] [PubMed]

228. Berzins, S.P.; Wallace, M.E.; Kannourakis, G.; Kelly, J. A Role for MAIT Cells in Colorectal Cancer. Front. Immunol. 2020, 11, 949. [CrossRef] [PubMed]

229. Martin, T.D.; Patel, R.S.; Cook, D.R.; Choi, M.Y.; Patil, A.; Liang, A.C.; Li, M.Z.; Haigis, K.M.; Elledge, S.J. The adaptive immune system is a major driver of selection for tumor suppressor gene inactivation. Science 2021, 373, 1327-1335. [CrossRef]

230. Cancer Cells' Unexpected Genetic Tricks for Evading the Immune System: Howard Hughes Medical Institute. Available online: https:/ / www.hhmi.org/news/ cancer-cells-unexpected-genetic-tricks-evading-immune-system (accessed on 11 October 2021).

231. Pu, D.; Yin, L.; Huang, L.; Qin, C.; Zhou, Y.; Wu, Q.; Li, Y.; Zhou, Q.; Li, L. Cyclooxygenase-2 Inhibitor: A Potential Combination Strategy With Immunotherapy in Cancer. Front. Oncol. 2021, 11, 248. [CrossRef]

232. Yan, G.; Zhao, H.; Zhang, Q.; Zhou, Y.; Wu, L.; Lei, J.; Wang, X.; Zhang, J.; Zhang, X.; Zheng, L.; et al. A RIPK3-PGE(2) Circuit Mediates Myeloid-Derived Suppressor Cell-Potentiated Colorectal Carcinogenesis. Cancer Res. 2018, 78, 5586-5599. [CrossRef]

233. Nivolumab, Ipilimumab and COX2-inhibition in Early Stage Colon Cancer: An Unbiased Approach for Signals of Sensitivity. Available online: https:/ / clinicaltrials.gov / ct2/show /NCT03026140 (accessed on 11 October 2021).

234. Koulouridi, A.; Messaritakis, I.; Gouvas, N.; Tsiaoussis, J.; Souglakos, J. Immunotherapy in Solid Tumors and Gut Microbiota: The Correlation-A Special Reference to Colorectal Cancer. Cancers 2020, 13, 43. [CrossRef]

235. Saha, T.; Dash, C.; Jayabalan, R.; Khiste, S.; Kulkarni, A.; Kurmi, K.; Mondal, J.; Majumder, P.K.; Bardia, A.; Jang, H.L.; et al. Intercellular nanotubes mediate mitochondrial trafficking between cancer and immune cells. Nat. Nanotechnol. 2021, 17, 98-106. [CrossRef] [PubMed]

236. Wang, C.; Sandhu, J.; Ouyang, C.; Ye, J.; Lee, P.P.; Fakih, M. Clinical Response to Immunotherapy Targeting Programmed Cell Death Receptor 1/Programmed Cell Death Ligand 1 in Patients With Treatment-Resistant Microsatellite Stable Colorectal Cancer With and Without Liver Metastases. JAMA Netw. Open 2021, 4, e2118416. [CrossRef]

237. Carlsen, L.; Schorl, C.; Huntington, K.; Hernandez-Borrero, L.; Jhaveri, A.; Zhang, S.; Zhou, L.; El-Deiry, W.S. Pan-drug and drug-specific mechanisms of 5-FU, irinotecan (CPT-11), oxaliplatin, and cisplatin identified by comparison of transcriptomic and cytokine responses of colorectal cancer cells. Oncotarget 2021, 12, 2006-2021. [CrossRef]

238. Groysman, L.; Carlsen, L.; Huntington, K.E.; Shen, W.H.; Zhou, L.; El-Deiry, W.S. Chemotherapy-induced cytokines and prognostic gene signatures vary across breast and colorectal cancer. Am. J. Cancer Res. 2021, 11, 6086-6106. [PubMed]

239. Huntington, K.E.; Louie, A.; Zhou, L.; El-Deiry, W.S. A high-throughput customized cytokinome screen of colon cancer cell responses to small-molecule oncology drugs. Oncotarget 2021, 12, 1980-1991. [CrossRef] [PubMed]

240. Ventola, C.L. Cancer Immunotherapy, Part 3: Challenges and Future Trends. Pharm. Ther. 2017, 42, $514-521$.

241. Liu, D.; Jenkins, R.W.; Sullivan, R.J. Mechanisms of Resistance to Immune Checkpoint Blockade. Am. J. Clin. Dermatol. 2019, 20, 41-54. [CrossRef] 